\title{
inovine
}

World Congress on

\section{Nursing and Healthcare}

July 15-17, 2019 Rome, Italy

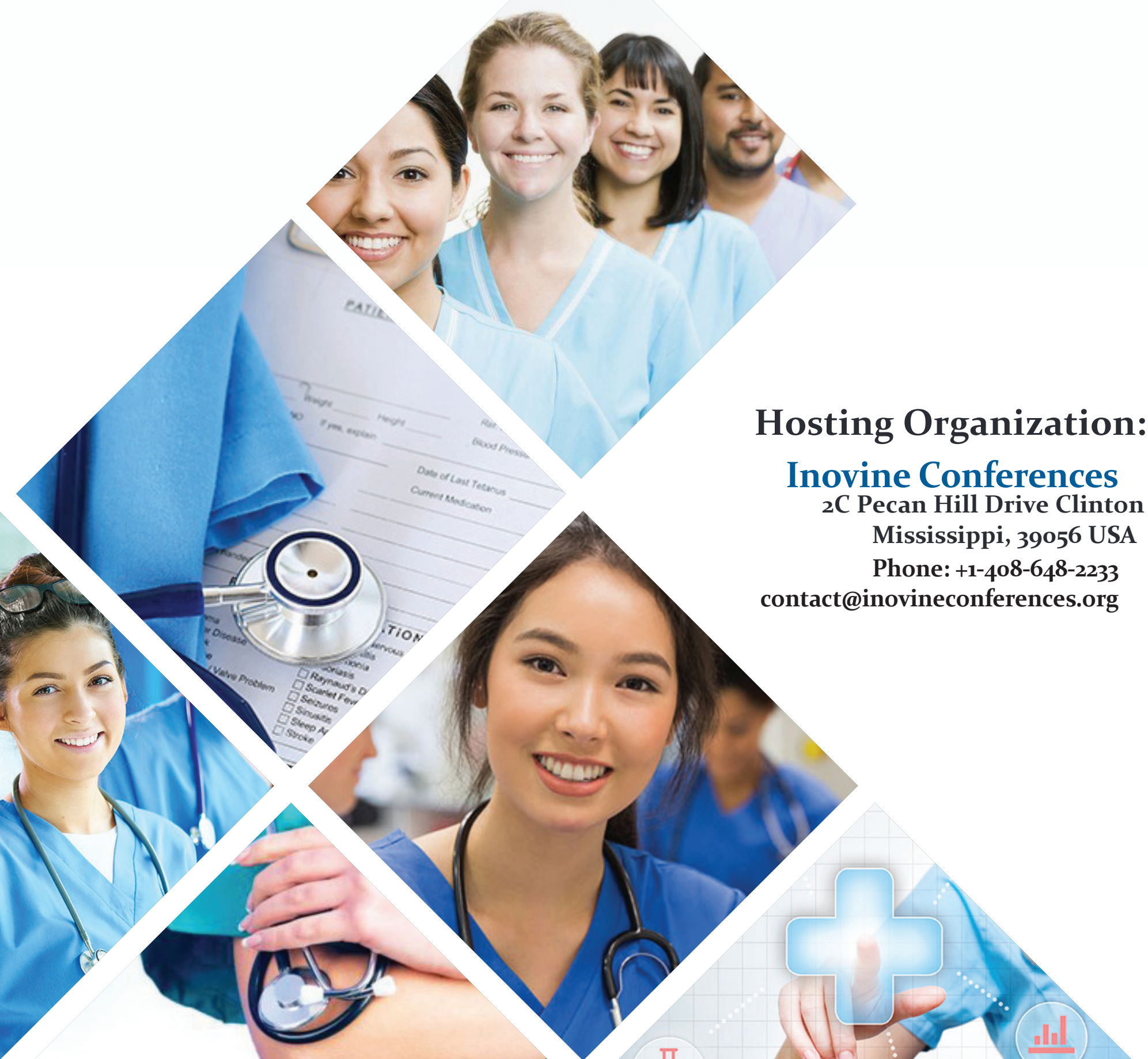




\section{NuRsing ANd HealthCare}

\section{July 15-17, 2019 | Rome, Italy}

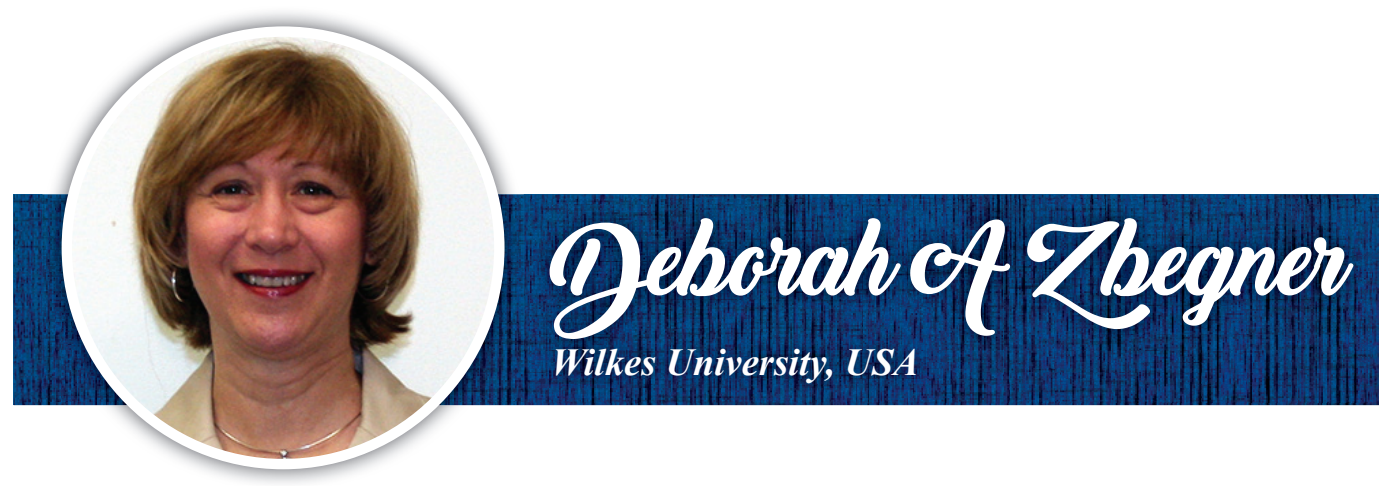

\section{A Dean's Journey: Revitalizing a School of Nursing}

Background: The School of Nursing, located within a small university residing in the northeast region of Pennsylvania, was joined with the School of Pharmacy and governed by the Pharmacy dean. The School of Nursing struggled with declining morale, mediocrity, identity, and attaining stellar board scores. The President decided that change was necessary and separated the schools, thus creating an independent School of Nursing. The task for the School of Nursing was to develop its own identity and flourish within the university and community. A search was conducted and a new dean emerged to lead the school.

Process: The process for change revolved around creating an organizational structure that would stimulate faculty, staff, and student productivity, increase overall morale, and create sustainable program growth. Faculty, students, and curriculum were analyzed separately and collectively within the context of the school and university. The first year focused on communication, conducting a SWOT analysis and extensively interviewing faculty, staff and students. A combined hierarchical matrix organizational design emerged and faculty and staff began functioning under the new structure.

Results: Four years later, the organization structure remains in place and the School of Nursing redefined its committee structure, process for evaluation, and the role of faculty and staff. The school is now endowed for 3.3 million dollars, increased its profile of programming, and has grown to approximately 1000 students between undergraduate and graduate departments. NCLEX-RN pass rates dramatically increased to above $90 \%$ for the past two years and Nurse Practitioner certification pass rates are consistent between 95 and 100\% depending on the program. The School of Nursing has increased its national visibility, prestige, and university support.

\section{Biography}

Deborah Zbegner was appointed dean of the first independent School of Nursing at Wilkes University in January 2015. She earned her Doctorate at Widener University, Master of Science in Nursing from the University of Pennsylvania, and her undergraduate Bachelor of Science in Nursing from DeSales University. She has 30 years of clinical practice as a nationally board certified women's health nurse practitioner and has 25 years of academic and leadership experience in higher education. Dr. Zbegner works in a collaborative physician practice caring for women across the life span and also serves as a clinical preceptor for nurse practitioner students within her practice site. Zbegner's academic knowledge, clinical expertise and national board certifications validates her commitment for promoting clinical excellence in all programs of the School of Nursing. She is a member of the PA Coalition of Nurse Practitioners of Northeastern Pa., National Association of Nurse Practitioners in Women's Health (NPWH), the Association of Women's Health, Obstetrics, and Neonatal Nursing (AWHONN), and Sigma Theta Tau International Honor Society of Nursing. Her research interests lie in education and clinical practice. 


\section{NuRsing ANd HeALTHCARE}

\section{July 15-17, 2019 | Rome, Italy}

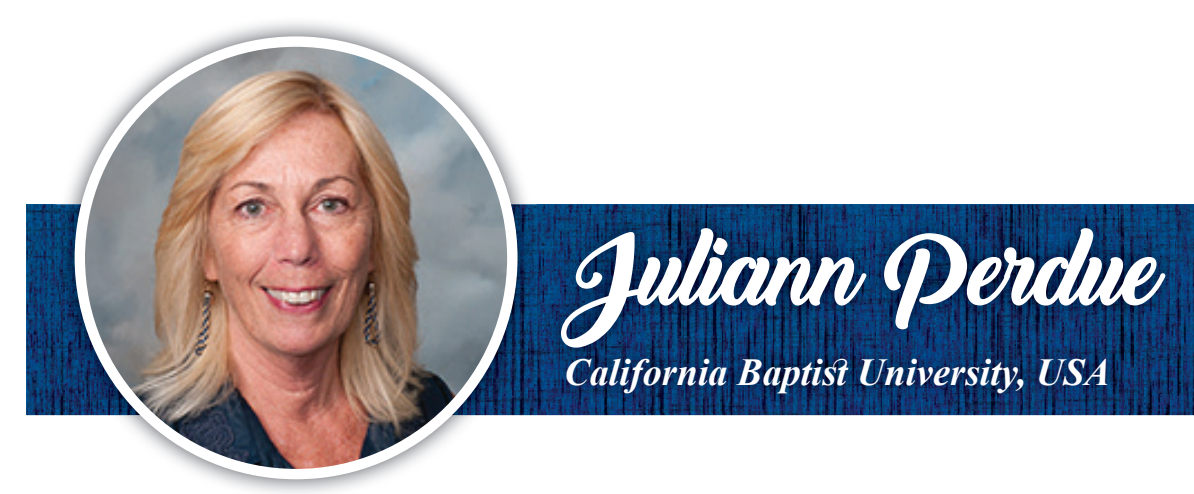

\section{Innovative Prelicensure Curriculum Using Animal-Assisted Interventions}

\footnotetext{
$A s$ an evidenced-based practice, animal assisted interventions (AAI) improve patient outcomes. Integrating animal assisted

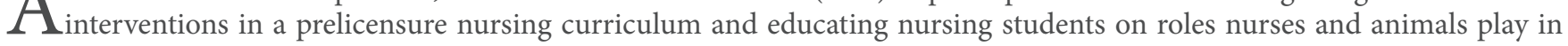
patient-centered care is an innovative strategy to improve care delivery.
}

Background: Understanding the human-animal bond is an important element of animal-assisted intervention and sets a foundation for nurses who will have knowledge, skills and attitudes necessary in this field. Positive patient outcomes for general health, mental health, child development and elderly health are associated with animal therapy. Integrating AAI meet the overall goal and competencies of the Quality and Safety Education for Nurses project.

Strategy and Implementation: Implementing this strategy utilized the integrated curriculum approach. Didactic and experiential course content was developed for nursing content areas. Faculty identified theoretical and clinical content for AAI to correspond with course objectives and learning outcomes. A certified therapy dog participated in animal assisted activities (AAA) with students, faculty, and community affiliates creating alternative clinical experiences.

Evaluation: A curriculum crosswalk tool listed each course and specific content. The tool summarized findings for content, learning objectives, activities, and evaluation of learning. The integration of AAI occurred at all levels of the nursing program. Students participate in leadership projects directly related to AAI and evidence-based practice.

Implications for Practice: The positive outcomes imply, the implication is to integrate AAI into nursing curricula with widespread dissemination in healthcare for improved patient-centered care and quality in care delivery. Further qualitative studies are underway to research student meaning of having therapy dogs and the role of nurses in AAI.

Learner Outcome: Identify two content areas for the integration of animal-assisted intervention in the nursing curriculum.

\section{Recent Publications:}

1. APPA National Pet Owners Survey. American Pet Products Association. http://americanpetproducts.org/pubs_survey.asp. Published 2017. Accessed June 2018.

2. Decourcey M, Russell AC, Keister KJ. Animal-Assisted Therapy: Evaluation and Implementation of a Complementary Therapy to Improve the Psychological and Physiological Health of Critically Ill Patients. Dimensions of Critical Care Nursing. 2010;29(5):211-214. Doi:10.1097/dcc.ob013e3181e6c71a.

3. Manor W. Directions for the Human-Animal Bond in the Nursing Education Curriculum. Holistic Nursing Practice. 1991;5(2):64-71. Doi:10.1097/00004650-199101000-00013.

4. Fine AH. Handbook on Animal-Assisted Therapy: Theoretical Foundations and Guidelines for Practice. Amsterdam: Academic Press/Elsevier; 2010. 
World Congress on

inovinè

NuRSING AND HeALTHCARE

July 15-17, 2019 | Rome, Italy

\section{Biography}

Juliann Perdue has her expertise in nursing education and animal-assisted interventions. She is a certified human-animal intervention specialist (CHAIS). Dr. Perdue has integrated animal-assisted therapy in the nursing curriculum at California Baptist University, volunteers in the community with her pet-partner Rugar, and provides guest lectures on the topic. She is a peer reviewer for the Journal of Rehabilitation Nursing and developed an integrative rehab model for practice based on the Theory of Integrative Nursing.

\section{Notes:}




\section{NuRsing ANd HeALTHCARE}

\section{July 15-17, 2019 | Rome, Italy}

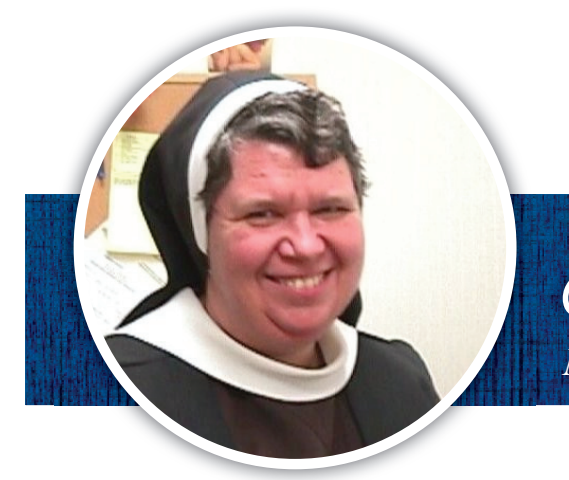

\section{Sr. QPetaria chlarie Indigk} Madonna University, USA

\section{Madonna University Partnership with the Felician Sisters Mission in Jacmel, Haiti Improves Healthcare and Provides Basic Needs for an Impoverished and Underserved Population in Jacmel Haiti: A Four Year Review (2014-2018)}

Background: Jacmel, Haiti is an impoverished and underserved state that is affected by past natural disasters, disease, and generations of systemic poverty. This rocky, mountainous area lacks running water, basic sanitation, and the people have little money and minimal job opportunities to pay for the basics of health, food, shelter, and education.

Objective: To examine how Madonna University's Partnership with the Felician Sisters' Mission in Jacmel, Haiti has helped the Haitian people in Jacmel with their needs for healthcare, food, and education over the past four years.

Conceptual Framework: Utilizing the Leininger's Sunrise Enabler Model, this study focused on assessing the needs of Jacmel, Haiti and showed how the partnership between Madonna University and the Felician Sisters' Mission is assisting the Hatian people.

Methods: Madonna University has participated in thirteen Mission Trips to Jacmel, Haiti over the past four years ( 2014-2018) to provide direct healthcare, health promotion education to adults, teens, and children, and needed health care supplies for 28 Mobile Clinic mountain sites, St. Michel Hospital, the Notre Dame School of Nursing and 3 orphanages in Jacmel, Haiti.

Results: The Madonna University Mission Teams have helped improve the health care of Jacmel through their work in the Mobile Clinic, home visits to give healthcare, distribution of over 150 water filter buckets, health promotion and education classes, as well as donations of medical supplies, medications, nursing equipment, eye glasses, and other supplies to help improve the health care, social needs, and education needs of the Jacmel region. Through the interventions of the Mission groups there has been a decrease in respiratory and skin infectious, less food borne diseases and gastric problems from contaminated water, increase of medical supplies, and improved healthcare delivery.

\section{Biography}

Sr. Victoria Marie Indyk, PhD, RN is a Professor of Nursing at Madonna University, Livonia, Ml and has taught nursing for 22 years in many levels of the undergraduate program. Education includes a BSN and MSN from Madonna University and a PhD in Nursing from Wayne State University, Detroit, MI. Over the course of her 44 years as a registered nurse, she has worked in a variety of healthcare settings and has been involved in many health related outreach programs. She has led 13 Mission Trips with nursing students and faculty from Madonna University to help the people of Jacmel, Haiti.

\section{Notes:}




\section{Two arms of the same scale: epidemiology and prevention of Group B Streptococcus agalactiae in a selected pregnancyNorthen Italian Population}

\section{Monari Marta Noemi}

Humanitas Research Hospital, Italy

Treptococcus agalactiae is well established as a colonizing agent in pregnant women and as an important cause of neonatal

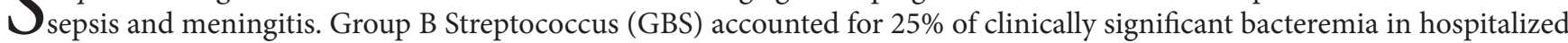
pregnant women in Ireland and $20 \%$ of hospitalized women with puerperal bacteremia in the United States. We have conducted a retrospective study on 10.252 pregnant women admitted in our hospital to do GBS swab, the actual method of GBS surveillance. We studied a media percentage of colonization of $14 \%$ and we found a significant difference year by years and by ethnicity during this ten years retrospective study. We concluded that this surveillance is fundamental to prevent infections in mother and child. In the future we want to study how differentiate the pregnant women in cluster of morbidity in order to identify whether the colonization positive data obteined by laboratory are in according with epidemiological data of literature.

\section{Biography}

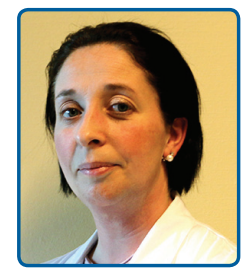

Marta Monari is a Biologist specialized in microbiology and virology with a II level master in virology and a Diploma en Genética Médica. She is the contract professor in two different Italian University: Humanitas Milano and Insubra Varese. She had worked as director of the clinical laboratory. Now she is the clinical and technical coordinator of laboratories of Humanitas Hospital group since $3 / 05 / 2018$, it is a group of 10 laboratories up $8 \mathrm{ML}$ of exams, divided in all laboratory specialties.

\section{Notes:}




\author{
African Americans Making the Decision to Become Living Kidney Donors: A Descriptive \\ Phenomenological Inquiry \\ Cherie L Smith \\ University of Phoenix, USA
}

\begin{abstract}
The purpose of this descriptive phenomenological study was to explore what it is like for African American participants 1 in Greensboro, NC to make the decision to become a living kidney donor. Additionally, their thought processes and experiences while making the decision to be or not to be a donor was explored. There are many reasons why people decide to become organ and living kidney donors. Many studies have been devoted to learning why people have decided to become organ donors or have studied living kidney donors after donation however, few have dealt with the experience while the potential donor is making the donation decision. Eight participants were purposely selected and interviewed in dialysis centers, private homes, and office settings. Data were collected and analyzed to identify experiences central to the problem of LKD among African Americans using Colaizzi's (1978) phenomenological method. QSR NVivo11 ${ }^{\circ}$ software was also used to assist with data management. Five themes emerged describing the essence of the African American experience of making the decision to become a living kidney donor including: Being fearful for my family member's life; being empathetic towards my family member; being concerned about my own health; being afraid my donated kidney will be damaged and go to waste; being motivated by my faith in God. Understanding the African American experience of making the decision to become a living kidney donor could assist health care providers and leaders with formulating a targeted approach to increase LKD in this atrisk population.
\end{abstract}

\title{
Biography
}

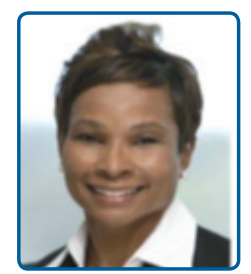

Cherie Smith is the Executive the Decision to Become Director of Nursing at cone Health in Living Kidney Donors: A Greensboro, NC. She is also served our Descriptive Phenomenological country for 24 years in the United States Air Force. Her previous educational Inquiry accomplishments include: BA (Psychology) BY CHERIE L. SMITH from St. Leo College, FI, BSN from South Carolina State University, SC, and MBA (Healthcare Administration) from Wayland. The purpose of this descriptive phenomenological Baptist University, TX. This year, 2018, Dr. Smith celebrates earning her PhD in Nursing study was to explore what it is like for African American from University of Phoenix.

\section{Notes:}




\section{Haemodialysis in a penitentiary: An Italian experience}

\section{Gabriel Naranjo Munoz}

Santi Paolo e Carlo, Italy

$\mathrm{K}$ idney disease is a substantial worldwide clinical and public health problem. Acute kidney injury (AKI) and chronic kidney disease (CKD) are linked to high health care costs, poor quality of life, and serious adverse health outcomes (including cardiovascular disease, kidney failure requiring kidney replacement therapy, infection, depression, and mortality). The economic burden of end-stage kidney disease (ESKD) continues to grow substantially. Future projections are for an increasing prevalence of ESKD globally, Worldwide, more than 2.5 million people were treated for ESKD in 2015 , this number is projected to more than double to close to 5 million people by 2030, with the highest growth in Asia . In the period August 2018 until today, Hemodialitic sessions have been performed, in an Italian penitentiary structure. The aim of our work is to study the feasibility that these dialysis services can be carried out assimilating the penitentiary structure to a CAL (Dialysis Centre for limited assistance)/CAD (dialysis Centre for decentralised assistance) using as a parameter the number of adverse events reported and as a quality indicator the reduction of economic expenditure incurred Although in the limited period and the reduced time of observation, we had no problems with this type of dialitic session poorly applied in places of long-term detention. We will continue the observation and registration of the outcome in order to guarantee the best continuity of care in respect of the reduction of costs (transport and assistance of police durin dyalitica session) in order to re-invest these savings in the sole interest of the clinical logic.

\section{Biography}

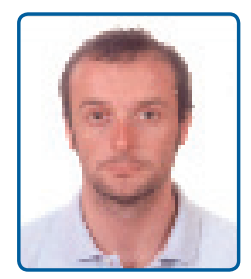

Gabriel Naranjo Munoz is a nurse that focused his attention on safety of patins in particular aroun maternity and collection blood samples. $\mathrm{He}$ is a contract professor in Italian university and he collaborates strictly with the project of clinical laboratory analisys of San Raffele Hospital He develops research project around safety, communications with patinets and taking care of them with the chif of laboratory and different units of the hospital.

\section{Notes:}




\title{
NuRsing AND HeALTHCARE
}

\section{July 15-17, 2019 | Rome, Italy}

\author{
Walk in Their Shoes: Dementia vs Delirium \\ Denise C Rhew \\ Cone Health, USA
}

\begin{abstract}
$\mathrm{A}$ $\mathrm{s}$ we, all know that the fast growing population in the United States is the older adult population aged 65 years or older. Approximately 37\% of older emergency department patients present with Cognitive impairment (most common Dementia/Delirium). Patients 65 years and older have the highest ED visits which result in a hospital admission. Every 33 seconds someone develops Dementia. Delirium is missed anywhere from $57 \%$ to $83 \%$ of time in the ED by providers because we do not screen for it! The problem is that the ED is a fast-paced environment and patients present with vague chief complaints, and often-altered mental status. It is imperative that nurses have the screening tools available to initiate individualize treatment plan, develop patient centered discharge, and disposition planning. Nurses have the ability and the responsibility to advocate for appropriate and safe care for all patients that enter into the hospital doors. Dementia versus delirium are often terms that often used interchangeably because they have similar symptoms. The way for nurses to ensure they can be advocates for their patients is to walk in their shoes and experience what they are going through. The purpose of this presentation is to give a brief overview of the differences between dementia versus delirium, provide participates with some communication techniques, and some hands on/simulations on auditory and visual changes using a sensory kit to be able to experience the impact of having dementia, delirium or both.
\end{abstract}

\begin{tabular}{|l|l|l|}
\hline & Delirium & Dementia \\
\hline Onset: & Acute & Gradual \\
\hline Conscious: & Impaired & Intact \\
\hline Symptoms: & Fluctuate & Progressive Decline \\
\hline Prognosis: & Reversible & Irreversible \\
\hline Memory: & Global & Remote Memory is Spared \\
\hline
\end{tabular}

\section{Recent Publications:}

1. Rhew, D., Letvak, S., \& McCoy, T.P. (2017). The Effects of an Educational Intervention on Emergency Nurses' Attitude, Knowledge, and Care Behaviors toward Older Adults. BioMedical Journal of Scientific \& Technical Research, 1(7).

2. Rhew, D., Owens, S., Kueider, S., \& Buckner, J. (2017). A Rural Hospital's Journey to Becoming a Certified Acute Stroke Ready Hospital. Journal of Emergency Nursing, 43(1), 33-39. DOI: https://doi.org/10.1016/j.jen.2016.10.016

3. ENA Topic Brief: Screening Tools for Older Adults in the Emergency Care Setting (2017) Contributing Author.

4. Letvak, S. \& Rhew, D. (2015). Assuring quality health care in the emergency department. Healthcare, 3, 726-732. doi:10.3390/healthcare3030726

\section{Biography}

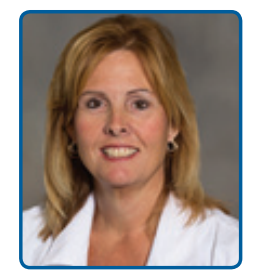

Denise Rhew is a Clinical Nurse Specialist for five emergency departments where she collaborates with physicians, ED leadership, and staff to provide clinical expertise to facilitate integration of evidence-based practice clinical standards, policies/procedures, guidelines, documentation, and quality improvement. Her dissertation was chosen as the Gerontology Dissertation of the year Award for 2016. Denise was selected as a North Carolina's Great 100 Nurse in 2005. She was chosen as the North Carolina Nurses Association Practice Nurse of the Year 2015 and the Nurse of Distinction for the Triad in 2017. Dr. Rhew was also selected as the Clinical Nurse Specialist of the year for the National Emergency Nurses Association in 2017. Dr. Denise Rhew's hopes is that she has encourage others to be passionate about learning, caring for others, and to have the desire to improving the compassionate nursing care provided to those who have entrusted their lives to nursing! 


\title{
NuRsing ANd HeALTHCARE
}

\section{July 15-17, 2019 | Rome, Italy}

\author{
The Development of a Clinical Portfolio as a Learning Approach for Intensive Care Nurses in a \\ Private Nursing Education Institution in Gauteng \\ Lizelle Potgieter \\ Fatima College of Health Sciences - Morocco
}

Clinical portfolios guide clinical learning experiences and assess the student's attainment of programme outcomes. The researcher experienced that neither the student nor the educator utilised the clinical portfolio effectively in the development and transformation of the intensive care nursing student at the private nursing education institution. The purpose of the study was to improve the structure and enhance the use of clinical portfolios as a learning approach in intensive care nursing education.

The study objectives for the study was:

Stage 1: to solicit the opinion of students and their educators on the quality of the existing clinical portfolio and their recommendations for the design and utilization of a revised clinical portfolio;

Stage 2: to design a revised clinical portfolio for intensive care nursing students based on educator and student opinion and literature review;

Stage 3: to solicit the opinion of nursing education experts on the revised clinical portfolio and to make changes as required.

This study is a shortened intervention research with qualitative methods for data collection from intensive care nursing students, lecturers, clinical facilitators, and nursing education experts. A content analysis (Tesch, 1990) was used for data analysis. The setting for this study was set in a private nursing education institution in Gauteng that offers the intensive care programme. Purposive sampling was used to select participants of the three focus groups. Students were not as concerned about the structure of the clinical portfolio as they were concerned about how the portfolio assists them in reaching their outcomes. Small changes were recommended. Educators and the literature were more concerned about the structure of the clinical portfolio and less concerned about the process of application. The clinical portfolio was redesigned to improve its function as a learning approach and is ready for piloting in larger sample groups.

\section{References}

1. Alsop, A. (2002). Continuing professional development: a guide for therapists. London: Blackwell Science Ltd.

2. Andre, K.E. (2011). Nursing and midwifery portfolios: evidence of continuing competence. Australia: Elsevier.

3. Birks, M., Hartin, P., Woods, C., Emmanual, E. and Hitchens, M. (2016). Students' perceptions of the use of e-portfolios in nursing and midwifery education. Nurse Education in Practice, 18, 46-51.

4. Brink, H., Van der Walt, C. and Van Rensburg, G. (2012). Fundamentals of Research Methodology for Healthcare Professionals. (3rd ed.) Cape Town: Juta and Company Ltd.

Biography 


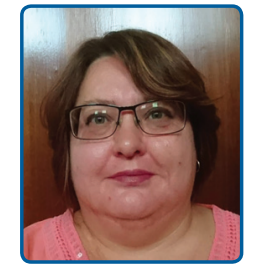

Lizelle completed BCur from the University of Pretoria in 1991, a Diploma in Medical Surgical Nursing Science from Netcare Education, affiliated with the University of the Witwatersrand, in 2006 and completing her Diploma in Nursing Education from The University of Johannesburg in 2008. Lizelle taught post basic nursing students from 2008 Medical and Surgical Nursing Science and completed her MSc Nursing in 2016 from the Faculty of Health Sciences, University of the Witwatersrand, South Africa, in fulfilment of the requirements for the degree of Master of Science in Nursing. She was awarded by the Golden Key International Honour Society for her study. She served on the Nursing Education Association Committee before leaving South Africa. She currently works in Morocco as the Academic Lead of Fatima College of Health Sciences in Rabat, teaching a Bridging programme to nurses who have a diploma in nursing that will culminate into a Baccalureus in Nursing.

\section{Notes:}




\section{Electronic nicotine delivery systems, adolescent use, and nicotine addiction}

\section{Debra Vincent and Jill Moore}

Indiana State University, USA

Problem: Electronic nicotine delivery systems (ENDS) or vaping use is surging amongst U.S. adolescents. The number of 8th through 12th graders using ENDS doubled from 2017 to 2018 (Miech et al., 2018). Juul ${ }^{\mathrm{mt}}$, a pod-based product, has a sleek design, is easy to conceal, comes in enticing flavors, and appeals to teens (McKelvey, Baiocchi, \& Halpern-Felsher, 2018; Sraders, 2018). Juuls ${ }^{\prime \prime \prime}$ impact on adolescents who vape is significant (McKelvey et al., 2018). The long-term effects of adolescent's vaping is not fully understood. Literature suggests substantial harm exists including nicotine addiction (National Institute on Drug Abuse, 2018). Complicating the problem of nicotine addiction is many adolescents are unaware ENDS contain nicotine (Truth Initiative, 2018).

Treatment: It is estimated that due to the nicotine addiction surge among teens, primary care providers, parents, educators, and teens themselves are seeking treatment options for nicotine addiction (Hoffman, 2018). Nicotine addiction treatments traditionally focus on adults. However, providers must now develop strategies for teens which target smoking cessation and nicotine addiction.

National Policy. The United States Food and Drug Administration ([USFDA] 2018a) has enacted policies regulating e-cigarettes; deeming tobacco products to be subject to the Federal Food, Drug and Cosmetic Act (USFDA, 2018b). These policies restrict the sale and distribution of all tobacco products to adolescents. National agencies struggle to stay abreast of the emerging ENDS technology (McKelvey et al, 2018; Truth Initiative, 2018b).

Provider Implications: Provider awareness of usage trends, device safety and product knowledge along with nicotine addiction treatment is imperative. Adolescents require education about what products are considered e-cigarettes, nicotine content, and nicotine addiction. Adolescent focused nicotine addiction treatment must be developed. Health care providers should screen adolescents for use of ENDs and consider vaping/smoking cessation counseling, and addiction treatment as needed for adolescents.

\section{Recent Publications:}

1. Hoffman, J. (2018, December 18). Addicted to vaped nicotine, teenagers have no clear path to quitting. The New York Times. Retrieved from https:/www.nytimes.com/2018/12/18/health/vaping-nicotine-teenagers.html

2. McKelvey, K., Baiocchi, M., \& Halpern-Felsher, B. (2018). Adolescents' and young adults' use and preceptions of podbased, electronic cigarettes. JAMA Netw Open, 1(6). doi:10.1001/jamanetworkopen.2018.3535

3. Miech, R. A., Schulenberg, J. E., Johnston, L. D., Bachman, J. G., O'Malley, P. M., \& Patrick, M. E. (December 17, 2018). "National Adolescent Drug Trends in 2018." Monitoring the Future: Ann Arbor, MI.

4. National Institution on Drug Abuse. (2018). Electronic cigarettes (E-cigarettes). Retrieved from https://www.drugabuse. gov/publicaitons/drugfacts/electronic-cigarettes-e-cigarettes

5. Sraders, A. (2018). What is Juul and is it bad for you? The Street. Retrieved from https://www.thestreet.com/lifestyle/ health/what-is-juul-14732885

Biography

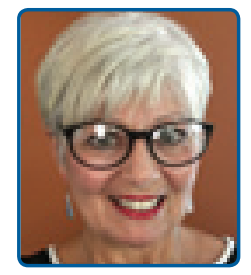

Debra Vincent has 23 years of expertise as a Family Nurse Practitioner (FNP) and is an Associate Professor in the Department of Advanced Practice Nursing, School of Nursing at Indiana State University. Debra is a FNP educator and practices in an urgent care setting. Her passion is cultivating and supporting FNP students' learning through online education. Her successful FNP practices include primary care in rural settings, occupational health on a nerve agent chemical plant, and urgent care. Debra's research focus is on promotion of wellness among school-aged children, including dental health, adolescent health, and their use of addictive substances, primarily nicotine via e-cigarettes. 


\section{NuRsing AND HealthCARE}

\section{July 15-17, 2019 | Rome, Italy}

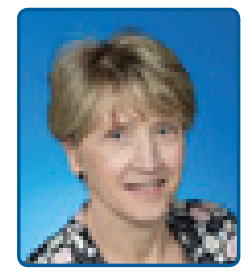

Jill Moore is the chairperson and an associate professor in the Department of Advanced Practice Nursing, School of Nursing at Indiana State University. She earned a PhD in Educational Leadership at Indiana State University. Her research focus is on policy and young adult success in the higher education environment. Jill's current nursing practice is in education; past nursing practice included critical care and medical-surgical care.

\section{Notes:}




\section{Compassion in the care of older people}

\section{Sanj Nathoo}

Buckinghamshire New University, UK

Background: Older people are amongst those in most need of compassionate care. Compassion, which can be demonstrated in 5 levels (compassion-, compassion, compassion+, compassion++ and compassion+++) is defined as the ability to appreciate and empathise with an appropriate action to ease suffering. Earlier research studies have explored patients' and/or qualified nurses' perspectives of compassion in nursing. This study is the first to explore compassion from the nurse educators' (NEs), clinical mentors' (CMs) and pre-qualifying nursing students' (PQNSs) varying perspectives.

Aim: To explore, discuss and evaluate views of compassion in the care of older people amongst nurse educators, pre-qualifying nursing students and clinical mentors.

Methods: A generic qualitative research approach was adopted using purposive sampling to recruit 39 participants (NEs=8, $\mathrm{CMs}=8$ and $\mathrm{PQNs}=23$ ). Semi-structured interviews yielded data that were analysed using framework analysis. Data collection was completed between July 2013 and February 2014.

Findings: Seven themes emerged: role modelling, working practices, care philosophy, clinical leadership, staff attitudes, quality care and nature and nurture. Role modelling was the dominant theme.

Discussion: This study adds to the literature by exploring multiple perspectives. Whilst pre-qualifying nursing students and clinical mentors favoured compassion from the perspective of humanistic role models, nurse educators valued compassion to demonstrate work practices, including competence.

Participants suggest that whilst enhancing quality care, compassion can speed up patients' recovery.

Conclusion: These findings show three stakeholders' perspectives and identify in what circumstances compassion is expected to flourish and when problems are likely to occur. From the accounts of these stakeholders, it is argued that compassionate care should be incorporated within practical sessions in the pre-qualifying curriculum and within care of the older person. In clinical practice, the perspectives on compassionate care identified by this study, can be embedded in its culture at all levels through nurse education and clinical leadership.

Biography

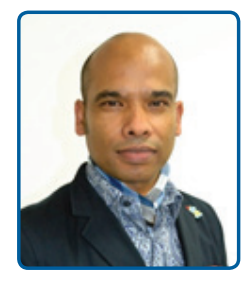

Sanj Nathoo (DProf, MSc, FHEA, Dip. Nurs, Ed. \& Health \& Safety) Sanj Nathoo qualified as a nurse in 1996, was promoted as a charge nurse in 1999 and started working in Higher Education in 2002. He is a Senior Lecturer/Professional Lead in Adult Nursing at the Buckinghamshire New University. Sanj has taught on many nursing courses at both pre and post graduate levels. He has experience in curriculum development and programme coordination. Sanj is a Fellow of the Higher Education Academy with Professional Doctorate in Nursing, Master Degree and a few Diplomas, namely in Education, Nursing and Occupational Health and Safety. He has a host of work as well as life experiences and can speak five languages. Sanj has presented at a few conferences, namely the NET conference at Cambridge University in September 2016. His research interests are 'compassion in nursing, safety and quality of care in nursing'. This year, he wrote in collaboration with a few international colleagues the following paper 'Does compassion matter in custodial care?' published in the International Journal of Mental Health Nursing. His current projects are 'compassion and preregistration nursing education' and 'compassion in the care of the older person'.

\section{Notes:}




\title{
Nursing ANd HealthCare
}

\section{July 15-17, 2019 | Rome, Italy}

\author{
Pressure Injuries and the Impact on Patient Quality of Life \\ Rachel Colletta \\ Director of Professional Education Acell, Inc. USA
}

$\mathrm{P}$ ressure injuries represent a significant issue which continues to impact patients worldwide across all healthcare settings. These injuries, which are often preventable, lead to increased morbidity and mortality, and significantly increase the cost of patient care. According to the Agency for Healthcare Research \& Quality (AHRQ), pressure injuries add an estimated \$9-\$11 billion dollars annually to healthcare costs in the U.S. Often overlooked is the impact on the quality of life of patients living with these injuries. Quality of life includes all aspects of patient health including, physical and emotional well-being, severity of symptoms and pain, social relationships, financial impact, and the patients' perception of health. According to national survey data reported in the Journal of Wound, Ostomy and Continence Nursing, the rate of pressure injuries has decreased by approximately fifty-percent from 2006 to 2016. This trend is thought to be a result of better treatment modalities, increased awareness, and the addition of monetary penalties by the Centers for Medicare and Medicaid Services. While this downward trend will decrease the number of patients affected by these injuries, it is important to focus on and address the needs of those who must manage these injuries while living their best life.

\section{References}

1. Are we ready for the change? Agency for Healthcare and Research Quality, Rockville, MD.https://www.ahrq.gov/ professionals/systems/hospital/pressureulcertoolkit/putool1. Last retrieved April 23, 2019.

2. Boyle, D. K., Bergquist-Beringer, S., \& Cramer, E. (2017). Relationship of Wound, Ostomy, and Continence Certified Nurses and Healthcare-Acquired Conditions in Acute Care Hospitals. Journal of Wound, Ostomy and Continence Nursing, 44(3), 283-292. doi:10.1097/won.0000000000000327

3. Gorecki, C., Brown, J. M., Nelson, E. A., Briggs, M., Schoonhoven, L., \& Dealey, C. (2009). Impact of Pressure Ulcers on Quality of Life in Older Patients: A Systematic Review. Journal of the American Geriatrics Society, 57(7), 1175-1183. doi:10.1111/j.1532-5415.2009.02307.x

\section{Biography}

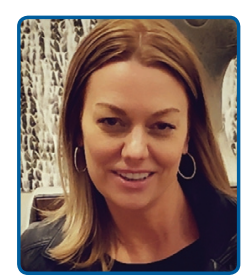

Rachel Colletta has been practicing nursing for over thirty years with experience in the areas of home care, home infusion, medical devices, life sciences, and nursing education. She graduated from a nursing diploma program and then went on to receive her BSN from Walden University. She holds several certifications in the areas of infusion therapy, immunoglobulin therapy, and vascular access. Rachel believes strongly that education leads to positive patient outcomes, and has been committed to the education of patients and healthcare professionals throughout her career.

\section{Notes:}




\author{
A Prescription For Academic Success: Integrating Physical Activity With Mental Health Services \\ \& Supports \\ Sheila John \\ University of Toronto, Canada
}

\begin{abstract}
$\mathrm{M}$ ental health issues among post-secondary students is on the rise. According to the Canadian Centre for Addiction and Mental Health, 1 in 5 Canadians experience mental health issues and young people aged 15-24 are more likely to experience mental illness than any other age group. Students arrive to university with goals in hand to achieve success, but the gap in health care is the importance of physical activity, to optimize health to ensure academic success. Students visiting the on-campus Health and Wellness Centre are seeking mental health supports for a range of issues including anxiety, depression, lack of sleep, and stress, but there is often a disconnect between the importance of physical activity when addressing mental health issues. To ensure optimal health of students, there must be training for health professionals and implementation of programs and services to encompass mental health and physical activity. Physical activity can help increase positive mood, decrease negative mood and stress, enhance academic success, reduce symptoms of anxiety and depression and foster quality of life among students. At the University of Toronto, a merge in programs between the Health \& Wellness Centre and Athletics and Recreation departments was implemented to determine the impact of overall health for students on campus. With training and education directed towards the synergy between activity and wellness, a range of programs were launched including the Healthy Campus Initiative. This initiative works to ensure that all aspects of the University are health-enhancing. Through focus groups and surveys and conducting research, evaluations have demonstrated the overall success of integrating programs related to mental health and wellness with physical activity and the positive impact to student's overall health and well being.
\end{abstract}

\title{
Recent Publications
}

1. Snedden, T. R. (2018). Sport and Physical Activity Level Impacts Health-Related Quality of Life Among Collegiate Students. American Journal of Health Promotion, 1-8.

2. Paluska, S. A., \& Schwenk, T. L. (2012). Physical Activity and Mental Health. Sports Medicine, 29(3), 167-180.

3. Biddle, S. (2016). Physical activity and mental health: Evidence is growing. World Psychiatry,15(2), 176-177.

4. White, R. L., Babic, M. J., Parker, P. D., Cubans, D. R., Astell-Burt, T., \& Lonsdale, C. (2017). Domain-Specific Physical Activity and Mental Health: A Meta-analysis. The American Journal of Preventative Medicine, 29(3), 653-666.

5. Herman, K. M., Hopman, W. M., \& Sabiston, C. M. (2015). Physical activity, screen time and self-rated health and mental health in Canadian adolescents. Preventative Medicine, 73, 112-116.

Biography

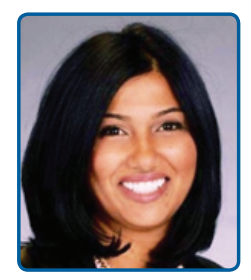

Sheila John is a registered nurse who is currently the Assistant Dean for Health, Wellness, Physical Activity, Recreation and Sport at the University of Toronto in Canada. She has a Bachelor of Science in Nursing from Ryerson University, and a Masters of Science In Nursing From D'Youville College in Buffalo, NY. Sheila has an extensive background in mental health with previous roles leading provincial and national mental health initiatives, teaching mental health courses, clinical educator for 6 mental health programs within a community hospital and a front line nurse in a psychiatric acute care setting. Her research background and passion has been related to mental health and has been involved in leading the development of evidence-based best practice guidelines for health professionals in Ontario.

\section{Notes:}




\author{
Using ICT to Replace the Face to Face Seminar for Teaching and Learning in Nursing Administration \\ Boontip Siritarangsri \\ Sukhothai Thammathirat Open University, Thailand
}

\begin{abstract}
$\mathrm{D}$ ue to increasingly Information and Communication Technologies (ICT) advancement application in education, the descriptive research was thus developed aiming to examine satisfaction and effect of using ICT to replace the Face to Face seminar for interactive teaching and learning in Nursing Administration. Participants were graduated students studying the Master degree program in Nursing Administration at Sukhothai Thammathirat Open University. The research tool consisted of a closed-end questionnaire in discovering the students' satisfactions; and open-ended in exploring the effective use of ICT. The tool was developed by researchers and verified by 3 experts. The content validity index was 0.83 . Research findings; 1 ) students were satisfied with using ICT to replace face to face seminar for interactive teaching and learning in Nursing Administration at the highest level $(\mathrm{M}=4.57, \mathrm{SD}=0.55)$. 2) The replacement of ICT led to the 3 following impacts on students: (1) learning skills conformed to needs in the 21st century, (2) deep learning, and (3) self-discipline and responsibility. The finding confirmed that ICT could be used as a replacement for face-to-face seminar in Nursing Administration. However, ICT application should rely on the objectives and characteristics of subjects as well as feedback process from instructors, particularly in the real time teaching.
\end{abstract}

\title{
Recent Publications:
}

1. Siritarungsri, B., Putapitakpol, S., Kaewpo, C., Onmanee, N.\& Sunato, P., (2017). Characteristics and Identity of Graduate Nurses Completing a Distance Learning System. ASEAN Journal of Open Distance Learning. Vol. 9, No. 2, December 2017.

2. Pugoy, RAD., Ramos, R.C., Figueroa Jr, R.B., Rivera, MHC., Siritarungsri, B., Cheevakasemsook, A., Noimuenwai, P. \& Kaewsarn, P., (2016). Augmented Reality in Nursing Education: Addressing the Limitations of Developing a Learning Material for Nurses in the Philippines and Thailand. International Journal on Open and Distance e-Learning, Vol. 2, No. 1, (June 2016): 11-23

3. Siritarungsri, B., Tubtheing, W. \& Maprangwan, S. (2015). Teaching English Reading Strategies on the Internet for Graduate Nursing Students". ASEAN Journal of Open Distance Learning, Vol. 7, No. 1, June 2015.

4. Siritarungsri, B (2015) "Power of Distance Education to Improve Nursing Leadership Competencies for ASEAN Nurses: Lesson Learned from an STOU's Online Course ", Proceedings "Roles of Distance Education in Human Resource Development" International Conference on Scientific Research 8-10 September 2015, NhaTrang, Vietnam

\section{Biography}

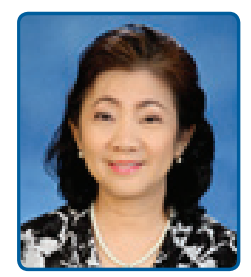

Boontip Siritarungsri is a nurse instructor at School of Nursing, Sukhothai Thammathirat Open University (STOU), Thailand that provides distance education, then 1994, she was appointed academic position as Associate Professor in nursing. Currently, Boontip is a registered nurse, faculty member, academic researcher with vast experience in nursing distance learning. Throughout 33 years in academic journey, she has significantly demonstrated her leadership in distance education, especially in nursing distance education, conducted a number of researches in innovative distance education particularly developing a successful short course training program. In her capacity as teaching staff, she has taught both undergraduate and graduate students. Her approach to teaching is guided by adult learning principles and she is committed to ensure students gain quality education experience irrespective of program delivery modality. She also obtained experience in research partnership nationally and internationally - Australia, Malaysia and the Philippines. 


\title{
NuRsing AND HeAlthCARE
}

\section{July 15-17, 2019 | Rome, Italy}

\section{Using Gaming For Nclex-Rn Preparation}

\section{Joyce Victor}

Wilkes University, USA

\begin{abstract}
The change in the NCLEX-RN ${ }^{\bullet}$ test plan in 2013 has led to a decline in first-attempt pass rates in many nursing programs.
1 As part of a larger study examining relationships of variables to first-attempt NCLEX-RN pass rates, this arm of the study was designed to examine the contribution of gaming strategies as a variable leading to an increase in first-attempt NCLEX-RN pass rates. Strategies such as coaching and gaming activities were implemented to provide opportunities for students to become more familiar with the NCLEX-RN blue print and content. The participants in the gaming activities program were senior-level nursing students. Nurse faculty members served as coaches. First-attempt NCLEX-RN pass rates were $75 \%$ at the initiation of the strategies. For the students who completed the gamification program, in addition to other programmatic preparation activities, first attempt NCLEX-RN pass rates increased by $10-15 \%$.
\end{abstract}

\section{Biography}

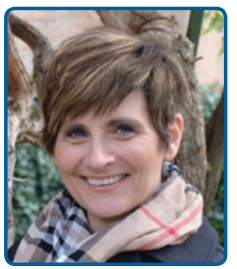

Joyce Victor, PhD, RN-BC, CHSE-A, is a graduate of NPW-Pittston School of Nursing. She has a BSN, MSN, MHA, and MA from Wilkes University. She earned her PhD from Duquesne University School of Nursing, where her dissertation on a theoretical model for simulation design won the outstanding dissertation award. She is coauthor of the International Standards of Best Practice for Simulation: Design, published by the International Nursing Association for Clinical Simulation and Nursing (INACSL). Victor has been the Director of the Clinical and Simulation-Based Learning at Wilkes University for the past fifteen years. She has been active in the American Heart Association on the local and state level. She is board certified in Professional Development through ANCC. She holds advanced certification as a Healthcare Simulation Educator (CHSE-A) through the Society for Simulation in Healthcare (SSH). Her research trajectory focuses on how preparing pre-licensure nursing students for entry into practice.

\section{Notes:}




\author{
Avoiding the mishaps of healthcare provision \\ Geneva M Edwards \\ Investigative Medicine LLC, USA
}

T egal Medicine consists of a broad range of legal, medical, and ethical issues, as well as human rights and rights of individuals. This discipline specialty is necessary in the healthcare profession because healthcare providers have a duty to act in a patients' best interest always. If healthcare professions fail to meet this duty they can and will be charged in a court of law. Medical Malpractice is defined as the legal cause of action that occurs when a healthcare professional deviates from the standard of care in his or her profession, thereby causing harm to a patient and happens when a patient is harmed by a healthcare professional who failed to meet the standard of care. When a healthcare provider does not meet the standard of care, they have breached their contract with their patient. The concept of the standard of care is often discussed among healthcare providers, and 14 yet the legal definition of this term is frequently not understood. It is estimated that $7-17$ malpractice claims are filed per 100 healthcare providers every year with emergency healthcare. providers on the front lines in healthcare provision and therefore are frequently involved in medical malpractice cases. Many healthcare professionals need to review evidence-based practices that focus on standard of care and review the best research and clinical expertise to assist them in meeting the needs of patients, far beyond optimum care provision; helping them avoid any mishaps along the way.

\title{
Biography
}

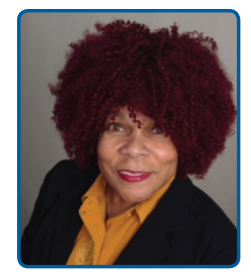

Edwards is a seasoned medical professional with $35+$ years of experience. She is a Registered Nurse, a Board Certified Medical Investigator, Legal Nurse Consultant, and a medical writer. She holds a Bachelor of Science in Nursing, a Master's in Health Administration, and a Medical Doctorate degree. She completed post-doctoral fellowship training in researching and analyzing medical data at CDC in Atlanta Georgia. Her passion lies in caring for the elderly and investigating what happens when medicine and law collide. For the last 8 years, Dr. Edwards has volunteered healthcare services to 3rd world countries, giving her the prestigious names of Dame of Honor, Dame of Grace and Grand Dame of the Cross.

\section{Notes:}




\title{
Nurse with MERS: Battling MERS-CoV Self-Experience
}

Najlaa Siddiq

King Faisal Specialist Hospital \& Research, Saudi Arabia

\begin{abstract}
healthcare worker became a patient in the ICU! This is a true story of what I experienced during an outbreak of MERSA CoV during 2014. It is very personal, in that not only did I have this experience of having MERS-CoV as a patient while being pregnant, but I am a survivor! I am living proof of how we at King Faisal Specialist Hospital have always strived beyond excellence to deliver quality care and address timely clinical issues encountered by nurses caring for Medical - Surgical patients within the critical care setting. Critical care nurses and other health professionals are involved in the provision of care to the ICU population and have the opportunity to engage in learning up-to-date and best practices relative to the daily management of critically ill patients.
\end{abstract}

By sharing my experience being a healthcare worker and ICU patient, I will be able to send message to healthcare workers all over the world:

What can all nurses take away from both research and your experience to better

Understand the ICU from the patient perspective

Care for the patient in the ICU

Care for the family of the ICU patient

\section{Biography}

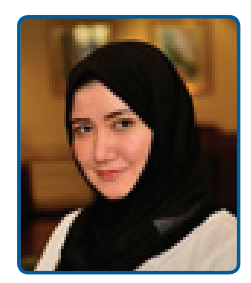

Najlaa Siddiq, who works in the Department of Nursing Practice Quality and Research as the Nurse Clinician for Clinical Services and as an Acting Quality Improvement Analyst. She graduated from King Abdulaziz University in 2003 with a Bachelor of Science in Nursing. When she joined King Faisal Specialist Hospital Jeddah in 2004, she worked in the Neuroscience unit until 2006.

In 2006, she enrolled in the Post Gradate Critical Care Nursing Diploma offered by our hospital and transferred to Medical Surgical Intensive care unit (MSICU) in 2007. She left there in 2014 to pursue a career development path into her present position. She has coAuthored and participated in two research projects: "Nurses' perception of professional shared governance at a multicultural hospital in Saudi Arabia" and "Deterioration after Initial Stabilization in Hypotensive Patients on the General Ward: An Outcome Analysis"

\section{Notes:}




\author{
Safe management of patient violence: Effective training programs for nursing students \\ Sally C Duron \\ California State University, USA
}

\begin{abstract}
The incidence of patient to nurse violence in hospitals and other healthcare facilities is increasing across the USA. RNs and 1 other healthcare workers are likely to experience 3 to 4 times higher non-fatal injuries than for all industry. Exposure to violence in healthcare is not limited to the USA but has also affected other countries. Presently research is being done in both the USA and Europe on the impact patient violence has on nursing students. Recent research validates an increase exposure students experience while performing activities in clinical settings. Mandatory training for nurses and other healthcare personnel is quickly being implemented throughout the USA that address patient violence in high risk areas. High risk areas have often been limited in the past to Mental Health and Emergency Services. However, today's reality is that patient violence now extends to venues including medical units, clinics, and social services. California has recently implemented regulations requiring training for all healthcare professional and trainees in the prevention and management of patient violence. Nursing students are provided skills to learn and develop competency in many areas related to the medical care. Today's nursing curriculums must include training and skills competencies on crisis intervention and the prevention of patient aggression and violence. This requires the development of diverse training programs to be implemented at the nursing undergraduate level. This workshop is intended to 1) share knowledge related to incidence, cause/risk factors, prevention, and interventions, and 2) how to develop and implement an effective training program. Sample existing training programs will be shared. Networking will be encouraged.
\end{abstract}

\title{
Publications
}

1. J Nurs Schorsh, 2011 Jun;43(2):203-10.doi: 10.1111/j.1547-5069,2011.01392.xEpub 2011 Apr1

2. International Journal Nursing Studies, Volume 51, Issue 1, January 2014, Pages 72-84

3. The Joint Commission. Improving Patient and Worker Safety: Opportunities for Collaboration \& Innovation. Oakbrook, IL.2012

4. Phillips JP. Workplace Violence Against Healthcare workers in the United States. New England Journal of Medicine, 2016; 374 (17):1661-9

\section{Biography}

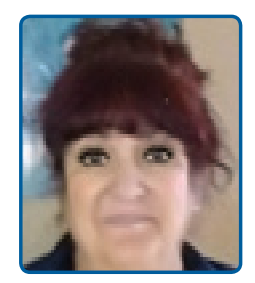

Sally Duron is presently an adjunct professor at California State University, San Bernardino, CA and West Coast University Ontario, CA. She is a Prevention and Management of Assaultive Behavior (PMAB) instructor. She has many years of experience as a Nurse Educator in the development of educational programs for medical professionals and students both within hospital educational institutes. She has a passion for integrating safe practice in all aspects of nursing care to improve the patience care experience. Her active participation in hospital base Performance Improvement, Safety, and Risk Management committees has allowed her to evaluate current risk factors, interventions from evidence base crisis models, and how to develop effective training programs that meet both professional and student competencies in management of patient violence in today's healthcare environment.

\section{Notes:}




\title{
Using a Geriatric Workshop to Change Emergency Nurses' Knowledge, Attitudes, and Care Behaviors toward Older Adult Patients who seek care in the Emergency Department
}

\author{
Denise C Rhew \\ Cone Health, USA
}

\begin{abstract}
$\mathrm{T}$ he problem that is exist is that nurses tend to hold negative attitudes about older adults. Nurses perceive the older adult patient vulnerability as an increase in their workload due to increased safety concerns and potential complex care needs. Nurses' knowledge and attitudes appear to affect their willingness to work with older people as well as the quality of care they provide for them. The purpose of this study was to examine the current knowledge and attitudes of Emergency Department Nurses on older adults. The study also explored the effect of an educational intervention on Emergency Department Nurses' attitudes and knowledge about older adults. Design: Quasi-experimental non-randomized pre-test, immediate post-test, and a four- week post-test design. Setting: A large healthcare system in the Southeastern United States that consists of five emergency departments and cares for approximate 750 patients daily between the five emergency departments. The sample consisted of a convenience sample that included Emergency Department Nurses, from five emergency departments from one hospital system in the South. Two instruments were used for this study Kogan Attitude toward Old People (KOP, 1961) tool and Palmore's Facts of Aging Quiz 1 (PFAQ, 1988). Method: Both the experimental and control group received three on-line surveys measuring knowledge and attitudes. The experimental group attended a Geriatric workshop (educational intervention) and completed the on-line pre-survey and immediate post survey at the workshop in a reserved computer room. The control group completed an on-line pre-survey and immediate post-survey at their convenience on the same day the geriatric workshop was being offered. Four weeks post geriatric workshop offering both the Experimental and Control group received an on-line post-post survey. Data analysis: Descriptive statistics was used to describe participant's characteristics. Reliability via internal consistency was estimated using Cronbach's alpha for Palmore's Facts of Aging scores (Knowledge) and Kogan's Attitudes toward Old People (KOP) scores (Attitudes). A simple independent t-test was used to compare baseline of the intervention groups' baseline knowledge and attitudes. Pearson's correlation was used to estimate the linear relationship between knowledge and attitudes along with a scatter-plot. Repeated measures ANOVA (RM-ANOVA) was performed to analyze mean differences of attitudes and knowledge scores between groups at pre-intervention, immediate post-intervention and approximately 4 week postintervention. The educational intervention (geriatric workshop) did improve knowledge, positive attitude scores, and changed care behaviors provided toward the older adults in the emergency room setting among the experimental group.
\end{abstract}

\section{Recent Publications:}

1. Rhew, D., Letvak, S., \& McCoy, T.P. (2017). The Effects of an Educational Intervention on Emergency Nurses' Attitude, Knowledge, and Care Behaviors toward Older Adults. BioMedical Journal of Scientific \& Technical Research, 1(7).

2. Rhew, D., Owens, S., Kueider, S., \& Buckner, J. (2017). A Rural Hospital's Journey to Becoming a Certified Acute Stroke Ready Hospital. Journal of Emergency Nursing, 43(1), 33-39. DOI: https://doi.org/10.1016/j.jen.2016.10.016

3. Letvak, S. \& Rhew, D. (2015). Assuring quality health care in the emergency department. Healthcare, 3, 726-732. doi:10.3390/healthcare3030726

\section{Biography}

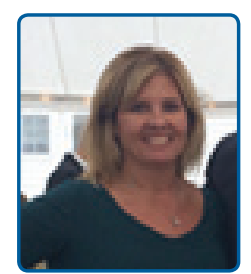

Denise Rhew is a Clinical Nurse Specialist for five emergency departments where she collaborates with physicians, ED leadership, and staff to provide clinical expertise to facilitate integration of evidence-based practice clinical standards, policies/procedures, guidelines, documentation, and quality improvement. Her dissertation was chosen as the Gerontology Dissertation of the year Award for 2016. Denise was selected as a North Carolina's Great 100 Nurse in 2005. She was chosen as the North Carolina Nurses Association Practice Nurse of the Year 2015 and the Nurse of Distinction for the Triad in 2017. Dr. Rhew was also selected as the Clinical Nurse Specialist of the year for the National Emergency Nurses Association in 2017. Dr. Denise Rhew's hopes is that she has encourage others to be passionate about learning, caring for others, and to have the desire to improving the compassionate nursing care provided to those who have entrusted their lives to nursing! 


\title{
NuRsing AND HeALTHCARE
}

\section{July 15-17, 2019 | Rome, Italy}

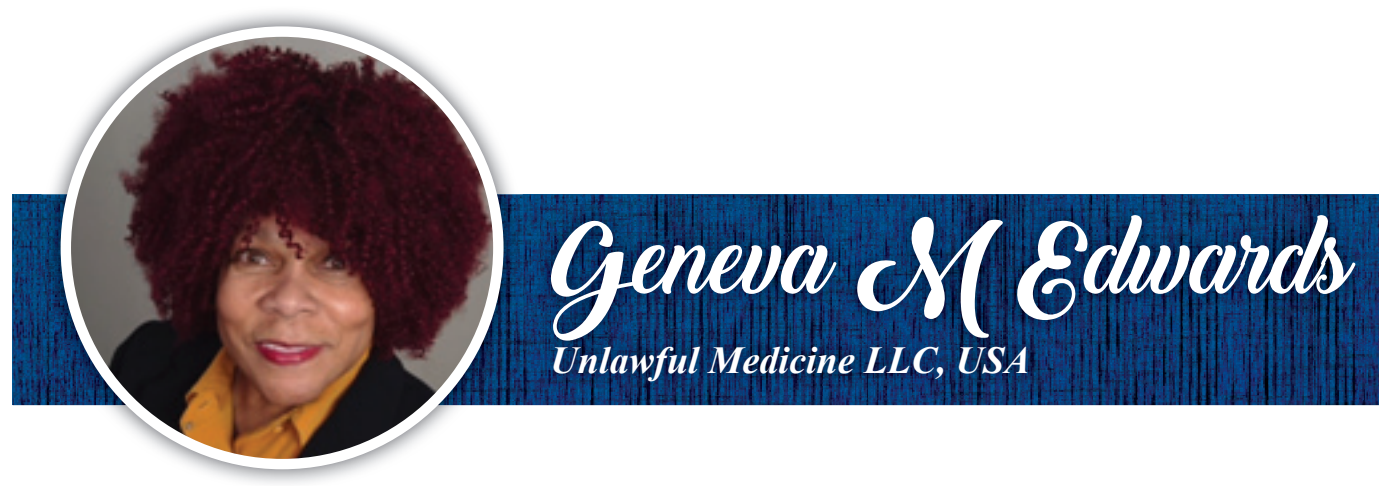

\section{Improving care of the geropsychiatric population in a complicated healthcare system}

\begin{abstract}
$A s$ a person ages there is a regression in both physical and mental health. This deterioration results in one's ability to deal

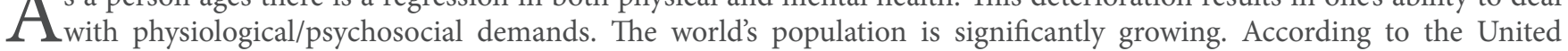
Nations World Population Prospects 2012, the average human lifespan is 70.7 years, 68.2 years for males and 73.2 years for females. According to the WHO, in the US, the human life expectancy is approximately 78.2 years for men and 81 years for women; predicting that within the next 35 years the proportion of the elderly is estimated to increase approximately $10 \%$. This is alarming because there is already a shortage of professionals who provide geriatric mental health services. In 2030 , it is estimated that there will only be approximately 1650 geriatric psychiatrists in the US; one geriatric psychiatrist per 6000 geriatric psych patient. Of the aging population, $20 \%$ have one mental disorder that has negative effects on their health. Research has proven that elderly are likely to have greater disability, worse health outcomes and higher rates of hospitalization and emergency services than older patients with just a physical condition. Last, not least, the cost per person with mental illness and a medical illness is estimated to be $50 \%$ to $200 \%$ higher than patients with a medical illness only. The geriatric population (65 years and older), is most likely to experience frequent, complex interactions with the healthcare system; a system so complex that it has trouble meeting their basic healthcare needs. Unfortunately, as the aging population increases so do mental disorders associated with aging (Alzheimer's Dementia, Anxiety, Major Depressive Disorder, Suicide Ideation, etc.). Therefore, the growing elderly community and the shortage of mental health services, underline the need to, initiate interventions, to improve care of the geropsychiatric population, in a complicated healthcare system.
\end{abstract}

\section{Biography}

Edwards is a seasoned medical professional with $35+$ years of experience. She is a Registered Nurse, a Board Certified Medical Investigator, Legal Nurse Consultant, and a medical writer. She holds a Bachelor of Science in Nursing, a Master's in Health Administration, and a Medical Doctorate degree. She completed post-doctoral fellowship training in researching and analyzing medical data at CDC in Atlanta Georgia. Her passion lies in caring for the elderly and investigating what happens when medicine and law collide. For the last 8 years, Dr. Edwards has volunteered healthcare services to 3 rd world countries, giving her the prestigious names of Dame of Honor, Dame of Grace and Grand Dame of the Cross. 


\section{NuRsing And HeAlthcare}

\section{July 15-17, 2019 | Rome, Italy}

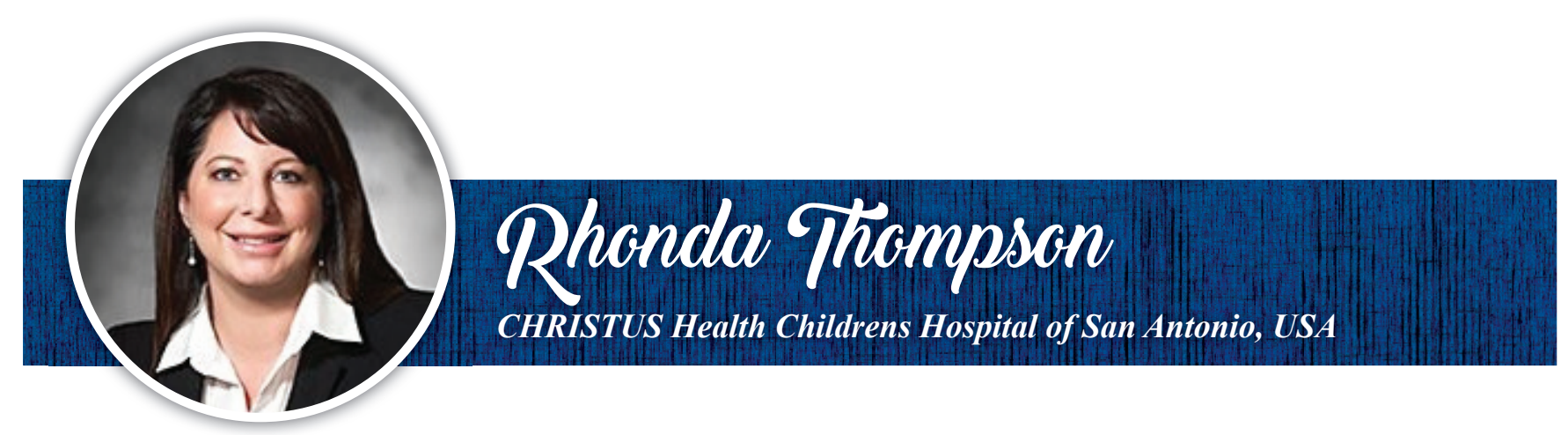

\section{Maternal Health, Morbidity and Mortality - CHRISTUS Health and the Texas Approach}

The United States has the highest maternal death rate among the world's developed nations. Texas is among the top ten 1 states with the worst statistics related to maternal deaths. In response, Texas developed the Perinatal Advisory Council to identify trends and recommendations to improve maternal outcomes. The council recommended criteria for designating levels of neonatal and maternal care, including specific minimum requirements to quality for each level designation and a process for the assignment of levels of care to a hospital. Texas also adopted the Alliance for Innovations on Maternal Health (AIM) safety bundles. CHRISTUS Health initiated a system approach led by the System Perinatal Executive Steering Committee. The intent of this committee is implement best practices and eliminate variation in practice across the entire CHRISTUS Health system. Using the criteria for levels of designation and AIM safety bundles CHRISTUS Health intends to provide every mother the highest quality and the safest care possible.

\section{Biography}

Rhonda Thompson is the Chief Nursing Officer at The Children's Hospital of San Antonio in San Antonio, Texas. She has over 25 years of experience in nursing, 10 years of leadership experience in adult, pediatrics, inpatient and ambulatory care. She is a member of the American Organization of Nurse Executives, Texas Organization of Nurse Executives, American Nurses Association and Society of Pediatric Nurses.

\section{Notes:}




\author{
Myelodysplastic syndrome and care of wounds, Pressure ulcers, White cell count and poor healing potential \\ Sylvie Hampton \\ Wound Care Consultants Ltd., UK
}

\begin{abstract}
$\mathrm{M}$ yelodysplastic syndromes (MDS) are a group of cancers in which immature blood cells in the bone marrow do not mature and therefore do not become healthy blood cells. Mr $\mathrm{H}$ had developed MDS 6 years previously which had been in remission for 3 years. MDS returned in July 2016 and he stopped eating. For a year he ate nothing solid. Nourishment was given in fluids. $\mathrm{Hb}$ varied between 50 and 70 and he had weekly blood transfusions. White cells were extremely low which meant healing would be negligible and clinical infection a high potential. April 2018 he was admitted to hospital with pneumonia. While in hospital he acquired flu, a pressure ulcer (Grade 4 sacrum), C-Diff (appalling diarrhoea) and lost all mobility as he was not permitted out of bed for 3.5 weeks. He also developed sepsis (Pseudomonas) which resulted in large black ulcers across his back and scrotum. Because of the MDS he should not have healed and the potential of infection, due to low white cell count, should have been a very high risk and yet he healed. Three dressings were used in healing these wounds. The first was a dressing pad that contained Ringer's solution. Used on the sacrum from commencement to healed. The second used on the abscess over the back was the pad that contained Ringer's solution, used to debride the wound and clean it. Then an activated carbon dressing used until healed. The third was a sheet gel dressing. This was used on all abscesses over the scrotum as it was the only dressing that would remain in situ. All of these wounds healed very successfully with this treatment.
\end{abstract}

Conclusion: It is vital that the condition of the patient is taken into account when deciding on dressings. No one dressing will cover all wounds.

\title{
Biography
}

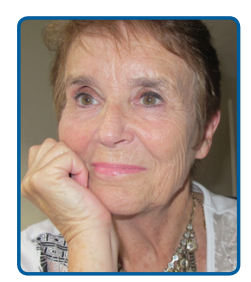

Sylvie Hampton. MA Bsc (Hons) DpSN RGN. Wound Care Consultant Nurse with twenty five years experience in wound care. 4 as enthusiast, 5 acting as specialist nurse in a hospital and 16 years as an independent consultant running a private wound healing centre commissioned by the NHS to care for chronic wounds. Having written over 400 articles and 2 books on wound care I am very experienced in treating and preventing wounds and in pressure ulcer prevention and treatment. Acting as: Trainer and advising nursing homes, District Nursing Teams, Practice Nurses and Hospital nurses. Expert witness for Coroners, Crown Court, Nursing and Midwifery Council and for Litigation cases. Specialist adviser for CQC which includes inspections of nursing homes, particularly involving tissue viability. Consultant and undertake research in wound care products, mattresses and seating for industry. Consultant for Lindsay Leg Club Foundation (LLCF) with several projects to complete including education, audit, co-authoring a Best Practice Compendium, writing articles and posters. Consultant for Marie Curie Hospice movement. Specialist adviser for CQC. Educator, organising study days and conferences. (International conference lectures have been with the Arab World Health Conference in Dubai, Geneva)

\section{Notes:}




\section{Caring For Bone Health in Breast Cancer Patients on Aromatase Inhibitors}

\section{Patricia A Karwan}

Women and Infants Hospital Care New England Health System, USA

Breast cancer continues to be one of the most common malignancies in developed countries, accounting for more than twenty-five percent of new cancer cases and fifteen percent of cancer deaths (Llombart, et al.,2012). Eighty percent of breast cancer patients are hormone receptor positive that benefit from the use of endocrine therapy. Aromatase inhibitors (AI's) suppress estrogen levels beyond what is experienced by natural menopause, which leads to a potential for accelerated bone loss ( Coleman, et al., 2013). AI associated bone loss occurs at a rate more than twice the rate of physiological post-menopausal bone mineral density loss which further fractures could result in pathological fractures, decreased quality of life (QOL), and decreased survival (Pedersini, et al., 2017). The focus of this study is to evaluate bone health management in the treatment of post-menopausal, hormone receptor positive, breast cancer patients on AI's. A retrospective chart review, totaling 47 hormone receptor positive post-menopausal breast cancer patients that were on AI's for at least three months was performed. Additional chart reviews were assessed if a dual-energy $\mathrm{x}$-ray absorptiometry (DEXA) scan was performed prior to initiation of AI's. Also evaluated were the ordering of calcium and vitamin D on identified patient with osteopenia or osteoporosis had they been on treatment. The results showed that sixty five percent of patients took calcium and vitamin D. Sixty three percent of patients had a pre-AI DEXA scan. Of the identified patients with a diagnosis of osteopenia or osteoporosis, only thirty one percent were placed on bone loss therapy. Implementing a standard of care to initiate therapy protocols for practicing clinicians will improve how the cancer treatment plan is followed and how it is documented accordingly.

\section{Biography}

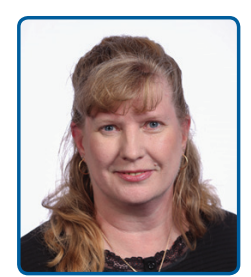

Patricia Karwan is An Adult Oncology Nurse Practitioner for Women and Infants Hospital at Care New England Health System. She is an Advanced Lecturer at Rhode Island College School of Nursing where she teaches graduate level Nursing. Her Master's in Nursing was received from Wayne State University in Michigan and completed her Doctorate of Nursing from Sacred Heart University in Connecticut. She is a member of the Oncology Nursing Society, Advanced Practice Society for Hematology and Oncology as well as a member of the Mu Delta Chapter of Sigma Theta Tau. She is a peer reviewer for Harborside Press on Oncology and Hematology Patients.

\section{Notes:}




\title{
NuRsing AND HeALTHCARE
}

\section{July 15-17, 2019 | Rome, Italy}

\author{
Pre-licensure experiences of nurses performing compulsory community service in KwaZulu-Natal, South Africa \\ Selverani Govender \\ Durban University of Technology, South Africa
}

Statement of the problem: Qualifying nurses from the four year diploma or degree in nursing have to carry out compulsory community service in public health institutions before their qualifications are registered with the South African Nursing Council. Studies on nurses carrying out compulsory community service (CCS) have been reported on the stresses experienced during their CCS year but there has not been much reported on how the nurses experience their roles and responsibilities during the CCS year.

Purpose: the purpose of the study was to explore pre-licensure nurses' experiences of their roles and responsibilities when carrying out CCS in KwaZulu-Natal.

Methods: A qualitative approach was used to obtain data from 27 purposively selected nurses carrying out CCS in three health districts of KwaZulu-Natal through individual semi-structured interviews. Data analysis was carried out using Tesch's content analysis.

Results: The main categories were: paying back the government or community, transition period for professional role, being thrown in the deep end, lack of role clarity, and frustrations with the policy.

Conclusions: Although the participants did not have a clear understanding of the objectives of the CCS policy, they seem to have taken on their role as professional nurses with enthusiasm and valued the opportunity to develop professionally.

Recommendations: It is recommended that nurse educators and administrators provide more clarity about the CCS objectives and that there is a structured orientation programme for the nurses on their roles and responsibilities when carrying out CCS.

\section{References:}

1. Bjerknes, M. S. \& Bjørk, I. T. (2012). Entry into Nursing: An Ethnographic Study of Newly Qualified Nurses Taking on the Nursing Role in a Hospital Setting Nursing Research and Practice, 2012, Article ID 690348, 7 pages. http://dx.doi. org/10.1155/2012/690348

2. Caliskan, A. \& Ergun, Y. A. (2012). Examining job satisfaction burnout and reality shock amongst newly graduated nurses, Procedia - Social and Behavioral Sciences 47, pp. $1392-1397$.

3. Hatcher, A.M., Onah, M., Kornik, S., Peacocke, J. \& Reid, S. (2014). Placement, support, and retention of health professionals, national, cross-sectional findings from medical and dental community service officers in South Africa, Human Resources for Health, 12 (14). http,//www.human-resources-health.com/content/12/1/14.

4. Parker, W., Nelia, R.D., Steyn, P., Mchiza, Z., Nthangeni, G., Mbhenyane, X., Dannhauser, A., Moeng, L. \& WentzelViljoen, E. (2013). Dietitians in South Africa require more competencies in public health Nutrition and management to address the nutritional needs of South Africans, Ethnicity \& Disease, 23 (Winter), 87-94.

\section{Biography}

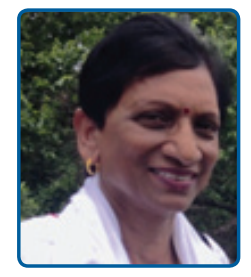

Selverani is a part time nursing lecturer in the Durban University of Technology which is situated in Durban, South Africa. This paper is one of many articles which analysed the implementation of compulsory community service in KwaZulu-Natal, South Africa in her PHD study. 


\section{The use of Community of inquiry methodology to enhance Journal Club effectiveness: a study protocol}

Paola Melis

Azienda Ospedaliero Universitaria di Cagliari, Italy

Statement of the Problem: Research skills are fundamental to evidence-based nursing practice. Journal clubs are an established practice to increase competence in evidence searching and appraisal. Nevertheless, there is a low participation of nurses in nursing research, both as researchers and as users of the results of the evidences. Moreover, it's not clear what are the factors enhancing JC effectiveness in terms of EBP outputs and it has to be better investigate the modulation exercised by the community of practice. In nursing education literature Dewey's seminal stance on reflection and critical thinking is a valued reference. Following Dewey's paradigms, Lipman develop his Philosophy for children/community proposal. P4C articulates in community of inquiry (being the scope and the educational tool at the mean time) and in a philosophical dialogue. According to many scholars the complex thinking, in its three dimensions of critical, caring and creative thinking, promote the argumentative reasoning and the community building skills. Our hypothesis is that the community of Inquiry, as promoted in P4C, could support the development of competencies needed to critical evaluate the evidence.

Aim: Our aim is to investigate the effectiveness of educational formats constituted by structured JC supported by P4C sessions versus standard structured JC format in improving EBP skills. It will be also investigated the development of the ability to produce dialogical argumentations.

Methodology \& Theoretical Orientation: we have planned an explanatory mixed methods approach. Nurse students at 3rd year course and staff nurses in continuing educational programs will be enrolled and allocated to receive either the JC formats supported by P4C sessions or the standard JC format. The JC formats are based on a collaborative approach between researchers (who will conduct them), clinicians nurses and student nurses. The co-participation of student nurses and nurse in the study is intended to help to bridge the perceived gap between academic studies and clinical settings and enhance a team culture. P4C sessions and JC meetings will be held twice a month for 1 year. Pre-post measures of EBP skills and attitudes will be conducted using the EBP questionnaire (Upton \& Upton). Focus groups at the end of the program will provide data to explore participants' perceptions of the formats within the frame of behaviour change theory. The coding system developed by Felton \& Kuhn will serve the pre-post assessment measure of argumentative discourse skills.

\section{References:}

1. Deenadayalan Y, Grimmer-Somers K, Prior M, Kumar S (2008) How to run an effective journal club: a systematic review. J Eval Clin Pract. 2008 Oct;14(5):898-911.

2. Goldstein A, Venker E, Weng C (2017) Evidence appraisal: a scoping review, conceptual framework, and research agenda. Journal of the American Medical Informatics Association, 24(6) 1192-1203.

3. Lizarondo et al.(2012) Does journal club membership improve research evidence uptake in different allied health disciplines: a pre-post study. BMC Research Notes 2012, 5:588

4. Macagno F (2016) Argument relevance and structure. Assessing and developing students' use of evidence. International Journal of Educational Research 1173.

5. Quitadamo IJ, Faiola CL, Johnson JE, Kurtz MJ (2008) Community-based Inquiry Improves Critical Thinking in General Education Biology. CBE-Life Sciences Education Vol. 7, 327-337.

Biography

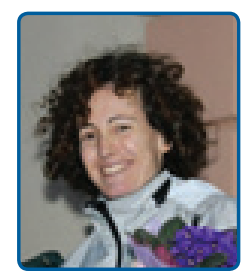

Paola Melis, RN, Master degree in Philosophy, Advanced Course in Bioethics, PhD student at URV, Lecturer at the University of Cagliari. Nurse educator with more than 12 years of service in postsecondary education. Long history of experience as a registered nurse in the hospital setting and some experience in international health organisations. She is involved in bioethics education for health personnel and she is co-founder of the Nursing Research Promotion Group of the University Hospital of Cagliari. She is involved in planning and constructing interdisciplinary pathways to favor health professionals' joint analysis of the ethical issues that arise in the clinical reality 


\author{
A Psychiatric Nurse Practitioners Led Urgent Care Office: Decreasing Emergency Room Visits \\ Pasqua Spinelli \\ Mather/Northwell Health, USA
}

Statement of the Problem: The lack of access to psychiatric services in health care has been a constant challenge for decades, resulting in significant delays to treatment with consequences in reduced quality of care, low patient satisfaction, poor patient outcomes, reduction in the

workforce and higher costs (National Council for Behavioral Health,2017). According to a March, 2017 report from the National Council of Behavioral Health (NCBH), a national shortage of psychiatrists is about to spiral out of control, with 77\% of U.S. counties reporting a severe psychiatrist shortage. Emergency departments have seen an increase of psychiatric patients in the last couple of years. This trend is related to the lack of access to mental health providers. Urgent care is defined as health care provided for the treatment of acute illness or

injury that is not life threatening (Urgent Care Association of America[UCAOA], 2011). Methodology \& Theoretical Orientation: In December 2017, a Psychiatric NP led urgent care office was implemented. After a year of collecting data from a retrospective chart review, 49 patients were seen from December 2017- December 2018 for urgent mental health issues. Findings \& Conclusion \& Significance: After a year of collecting data from a retrospective chart review, 49 patients were seen from December 2017- December 2018 for urgent mental health issues. Two patients required police intervention to be taken to hospital for inpatient admission due to an active suicidal plan. As part of a solution in alleviating overcrowded EDs for patients with life threatening needs, urgent care centers serve as a viable alternative (UCAOA,2011). The Psychiatric Nurse Practitioner in an urgent care setting is educationally prepared to provide comprehensive psychiatric management to patients and most importantly effective in decreasing Emergency Room visits and in addition increase patient satisfaction and patient safety. Recommendations are made for adding urgent care centers to address psychiatric issues.

\title{
Biography
}

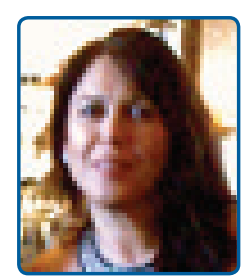

Pasqua Spinelli received her PhD from Capella University and her undergraduate Nursing degrees from Adelphi University, Garden City New York. She currently is the Family Psychiatric Mental Health Nurse Practitioner in an outpatient setting on Long Island, New York. She also provides consultation to attorneys in medical malpractice cases as a Legal Nurse Consultant and Sexual Assault Nurse Examiner.

\section{Notes:}




\author{
Midwifery and Nurses knowledge and attitude on breastfeeding, Al Wakra Hospital, Qatar \\ Jussara Brito \\ Hamad Medical Corporation, Qatar
}

Statement of problem: The professional health care as a supporter in help mothers and families to continue decision to breastfeeding exclusively until 6 months. However, on the other hand, the attitude of health professionals may also negatively influence mothers' perceptions about breastfeeding and its benefits. The purpose of this study to evaluate knowledge and attitudes on breastfeeding among Staff Nurses on the Obstetrics \& Gynecology Al Wakra Hospital. Methodology: A cross sectional descriptive survey carried out among all staff at Ob \& GY. The data was collected through face-to-face interview using a structured questionnaire $(n=163)$. The questionnaire ${ }^{\star}$ as composed by 21 questions. The questions cover a range of information in economy e.g. Formula feeding is more expensive than breast-feeding", nutrition e.g. "Breast milk is the ideal food for babies", convenience e.g. "Breast-feeding interferes with a couple's sexual relationship", e.g. infant bonding "Breastfeeding increases mother-infant bonding", composition and protection e.g. "micronutrients that may not be available", e.g. "baby more likely to develop diarrhea" and, attachment e.g. "more of the areola above". Linear Pearson correlation and simple linear regression analysis were used to investigate the relationship between variables. Conclusion \& Significance: In spite of the general awareness of the advantages of breastfeeding, misconceptions, negative attitudes and strong cultural belief found in this study suggest a need to emphasize the long-term benefits of exclusive breastfeeding for all staff independently of participation or not in breastfeeding course before to improve the social and professional acceptance of breastfeeding. Staff breastfeeding knowledge and attitudes were strongly associated with breastfeeding practice in this study, those who were less knowledgeable (new staff or staff that did the course more than 2 years) should be targeted for breastfeeding education, interventional practice and reflection.

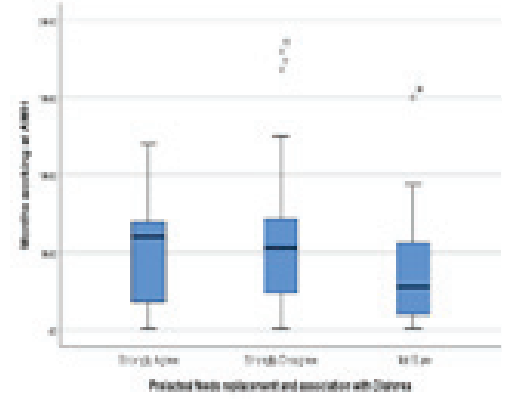

Table 1. Distribution of Prelacteal feeding and Diarrhea, AWH, Doha.

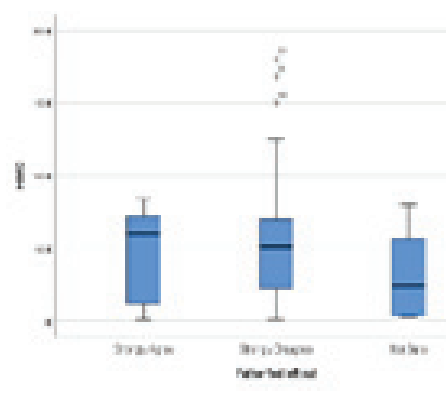

Table 2. Breastfeeding and father's feeling, AWH, Doha, 2018

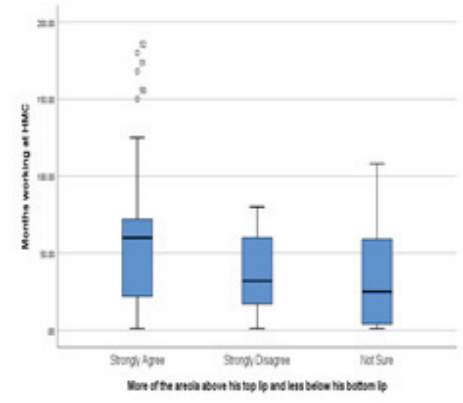

Table 3. More of areola above lips, AWH, Qatar.

\title{
Bibliography
}

1. Brand E, Kothari C, Stark MA. Factors related to breastfeeding discontinuation between hospital discharge and 2 weeks postpartum. J Perinat Educ. 2011 Winter; 20(1):36-44. doi: 10.1891/1058-1243.20.1.36.

2. Brand E, Kothari C, Stark MA.Factors related to breastfeeding discontinuation between hospital discharge and 2 weeks postpartum. J Perinat Educ. 2011 Winter; 20(1):36-44. doi: 10.1891/1058-1243.20.1.36.

3. Nelson JM1, Li R2, Perrine CG2. Trends of US hospitals distributing infant formula packs to breastfeeding mothers, 2007 to 2013. Pediatrics. 2015 Jun; 135(6):1051-6. doi: 10.1542/peds.2015-0093.

4. Verd S, de Sotto D, González T, Villalonga B, Moll J. Disparity between paediatricians' knowledge and practices regarding breastfeeding. Acta Paediatr. 2007 Nov; 96(11):1712-3.

5. UNICEF. A letter from Anthony lake, Executive Director of UNICEF on the Occasion of World Breastfeeding week 2013. Office of Executive Director. United Nations Children's Fund. New York, 2013 


\section{July 15-17, 2019 | Rome, Italy}

\section{Biography}

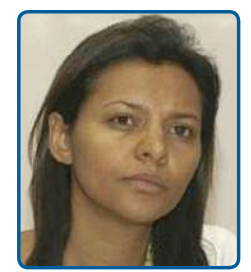

Jussara Brito, served as the Director of Health care Community in Brazil from 1990 to 2015 she worked in implementation of public and universal Brazilian's System (SUS Brazil). In 2007 to 2009 she works as a United Nations/Brazilian consultant at Brazil Government in Evaluation of Dengue National Program. She holds a Degree in Nursing from the University of Santa Maria and, as well as, a Masters of Public from National Public Health School of Rio de Janeiro, From 2017 she is working at Al Wakra Hospital in Doha, Qatar at Obstetric and Gynecological Department. The principal projects: Breastfeeding and Mental Health implementation.

\section{Notes:}




\title{
The Meaning of Adolescent Mothers Experience with Childrearing and Studying Simultaneously
}

\section{Benyapa Thitimapong}

Prince of Songkla University, Thailand

\begin{abstract}
Teenage pregnancy and adolescent mothers have become a matter of increasing concern in a great number of countries and 1 also in Thailand. The majority of pregnant students and adolescent mothers dropped out of school after becoming pregnant and some of them return to study again after they gave a birth. This research aimed to explain the meaning of adolescent mothers who had undergone with childrearing and studying simultaneously after childbirth. A phenomenological qualitative approach was undertaken to investigate this study. The participants were 20 adolescent mothers each of whom became a mother and a student concurrently within less than 2 years after giving birth to a healthy baby and had also undergone the experience of childrearing and studying in a non-formal education. In-depth interview was carried out for data collection, and the data were analyzed using content analysis method. "Learning to move forward" was the meaning of adolescent mothers who experienced with childrearing and studying simultaneously. Their expressions were classified into two categories 1) having more responsibility, and 2) conceding and going on. The result of this study can be used as an evidence for health care providers, especially nurses to facilitate and support pregnant adolescents and adolescent mothers to continue their education. Also, it can be used to guide a policy to promote in all educational system to enable these groups to remain in school for their life-long success in the future.
\end{abstract}

\section{Biography}

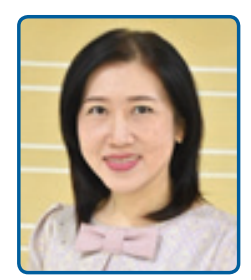

Benyapa Thitimapong is a fulltime lecturer at faculty of Nursing, Prince of Songkla University, Thailand. My interested area study is adolescents and qualitative study. 


\section{Perceived Barriers of Physical Activity among Saudi Female Adolescents in Jeddah, Saudi Arabia}

\section{Eman Z Bajamal}

King Saud bin Abdulaziz University for Health Sciences, Kingdom of Saudi Arabia

$\mathrm{D}$ espite health benefits of physical activity (PA), only $25 \%$ of female adolescents meet WHO and ACSM-PA recommendations calling for 60 minutes of PA daily (Al-Hazzaa et al., 2011). The level of PA is lower among female adolescents who are in the high school or with low family income. The purpose: To examine relationships among perceived barriers of PA and the level of PA, and to identify sociodemographic differences in perceived barriers of PA. The results: the student's mean age was 15.43 years $(S D=1.68)$. The largest percentage represented 13 years old females $(21.9 \%)$ and slightly more than half of the study participants' were from high schools (50.9\%). Also, the largest percentage represented fathers whose education was the undergraduate degree or higher (55.1\%), compared to the mother education (47.3\%). In addition, the largest percentage was associated with having a family income between SR7,000 and SR15,000 (28.2\%). Perceived barriers were positively and weakly correlated with age $(r=.00, p=.902)$ and negatively and weakly correlated with self-reported PA $(r=-.20, p<.001)$. There were significant BMI differences in perceived barriers $(p=.023)$. The overweight participants had significantly higher perceived barriers to PA $(M=1.48, S D=.45)$ than the participants with a normal weight $(M=1.32, S D=.41)$.

Conclusion: The significant negative correlation between perceived barriers of PA and PA indicates that helping adolescents especially overweight or obese.

\section{Biography}

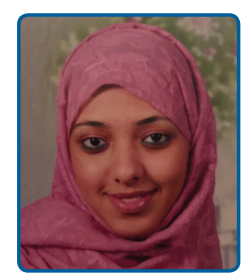

Eman is an Assistant Professor and Chairperson of Nursing Department in the College of Nursing at King Saud bin Abdulaziz University for Health Sciences, Jeddah, Saudi Arabia. Dr. Eman received her Bachelor degree in nursing science from King Abdulaziz University, her Master in Community Health Nursing from Wayne State University, and her PhD from Michigan State University.

\section{Notes:}




\section{July 15-17, 2019 | Rome, Italy}

\section{Burnout and Departure Intentions}

\section{Yaser Sweed}

Galilee Medical Center, Israel

Background: The increase in the turnover of the nursing staff is a troublesome phenomenon both for organizations that employ them and for the patients who need them. This is expressed in the expenses borne by the organization, with considerable investment in the recruitment and training of new staff, and is also expressed in the decline in the level of care for those who need it when talking about new workers. It is important to examine the influence of the satisfaction and burnout of the nursing staff in the hospitals on their intention to leave the job.

Research Objective: To estimate the different factors that lead to the intention of departure among the employees in health organizations.

Research Type and Research Population: Cross-sectional research, including nursing staff in the Galilee Medical Center.

Research Instruments: A questionnaire composed of sub-questionnaires: (1) satisfaction at work, (2) intention to depart, (3) burnout at work, (4) source of stress questionnaire, and trust in the manager questionnaire.

Findings: In the research 210 nursing staff members participated, 70.5\% (148) were women. The mean age of the research participants was $38.5 \pm 9.6$, with a mean of professional experience of $13.5 \pm 10.8$. The research findings showed that there is a significant positive relationship between burnout and departure intentions $(r=0.648, p=0.000)$. In addition, a significant negative relationship was found between burnout and satisfaction $(r=-0.475, p=0.000)$. A significant negative relationship was found between satisfaction and departure intentions $(\mathrm{r}=-0.517, \mathrm{p}=0.000)$. In addition, a positive relationship was found between the source of stress and departure intentions $(\mathrm{r}=0.359 ; \mathrm{p}=0.000)$ and a statistically significant negative relationship was found between the worker's trust in the direct manager $(r=-0.344, \mathrm{p}=0.000)$ and the departure intentions $(\mathrm{r}=-0.344, \mathrm{p}=0.000)$.

Summary: The significance is that the load and stress at work may cause lack of satisfaction, absences, and departure from the work place.

\section{References:}

1. Bonner G.P (2012). Touched by violence and caring for the violator: The lived experiences of nurses who were assaulted by their patients in psychiatric settings. Doctoral dissertation, Capella University

2. Bradley D.M (2012). A qualitative study of violence and victimization perpetrated against registered nurses in the workplace. Doctoral dissertation, Capella University.

3. Hahn S., Muller M., Needham I., Dassen T., Kok G., \& Halfens R. JG (2010). Factors associated with patient and visitor violence experienced by nurses in general hospitals in Switzerland: a cross-sectional survey. Journal of Clinical Nursing, 19 , pp. 3535- 3546.

4. Healy. s., and Tyrell M. (2011). Stress in emergency department experiences of nurses and doctors. Emergency nurse 19(4), Pp. 31-37.

5. Hahn S., Needham I., Kok G., Dassen T., Halfens R. JG. (2009). Aggressive Behavior of Nursing Home Residents Toward Caregivers: A Systematic Literature Review. Geriatric Nursing. 30(3). Pp. 3535-3546.

\section{Biography}

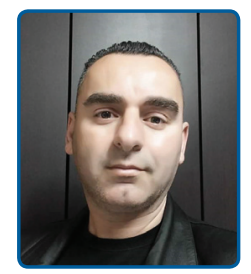

Yaser Sweed was born in the village of Peqiin in 1970. He studied elementary and high school in the village and finished high school in the galilee comprehensive school. He decided to continue his studies and chose the profession of nursing, at the Shaare Zedek nursing school in Jerusalem. He has a bachelor's degree in health systems management and today he continue his MA in the same field. He work in an internal ward at a Galilee medical center in Naharya. 


\author{
The meaning of self-leadership for nure educators conducting research \\ Karien Jooste \\ Cape Peninsula University of Technology, South Africa
}

Statement of the Problem: Self-leadership is the process in which people should direct and motivate themselves to behave and perform in a desired way in order to take responsibility for creating the conditions that help them to achieve set goals. Selfcoaching through constructive thoughts and sharing of ideas could enhance the perceptions of self-leadership of individuals. In an environment of merging a university with nursing colleges, a team approach is needed to capacitate nurse educators to contribute to research output. The purpose of the study was to develop a research academic program for lecturers. The research explored nurse educators' concerns regarding their development as novice researchers and leaders.

Methodology \& Theoretical Orientation: Constructivism was followed with the beliefs that learning is interactional, active and relative. Participatory research was initiated and narratives written by twelve academics. This was followed by three groups each with four lecturers critically reflecting on the topic. Their brainstorming was then presented in a drawing. Open coding was conducted.

Findings: The pictures indicated various shapes, conceptual meanings, picture sizes, different aspects on different position, details such as time constraints, sizes of the details, facial displays, words and symbols. Themes came to the fore with categories. Research was seen as a journey, with positive and negative steps of a variety of aspects from grants, supervision of students, own studies, partnerships.

Conclusion \& Significance: The importance of this study is for nurse educators to identify with a research process as a lifelong process of scholarship while developing professionally in leading themselves forward. Resources was a major challenges while confidence in conducting research was hampering their partaking in own research. The way in which lecturers see their own world of research varied.

\title{
References:
}

1. Armstrong S (2017) Bringing policy to fruition in training South African nurses. Retrieved from Mail and Guardian: https://mg.co.za/article/2016-05-13-00-bringing-policy-to-fruition-in-training-south-african-nurses.

2. Frantz J, Filies G, Jooste K, Keim M, Mlenzana N, Laattoe N, Roman N, Schenck R, Waggie F, Rhoda A (2016) Reflection on an interprofessional community-based participatory research project. AJHPE 8 (2):234-237.

3. Jooste K, Maritz J (2014) Youths' experience of trauma: Personal transformation through self-leadership and self-coaching. African Journal for Physical, Health Education, Recreation and Dance 2: 91-106.

4. Jooste K, Frantz J, Waggie F (2017) Challenges of academic healthcare leaders in a higher education context in South Africa. Educational Management Administration \& Leadership 1:17

5. Jooste K, Shanaaz M (2015) Self-Leadership of Male Learner Nurses During a Four-Year Program at a College in the Western Cape South Africa Journal of Psychological Issues in Organizational Culture 5 (4):53-72.

Biography

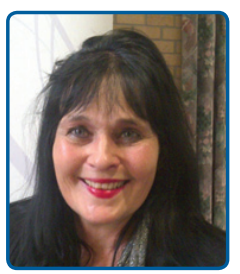

Karien Jooste is an editor/author of various prescribed textbooks in the field of nursing leadership and health care service management, supervision and ethos and professional practice. and her first publication on preceptorship (staff development) was published in 1995. She has presented at and formed part of numerous organising committees of international nursing and health care conferences in more than 40 countries. She has developed and offered leadership short courses for nurse managers in the mine industry. She is currently busy with independent research, due to National Research Foundation Grant to conduct research in self-leadership of the youth in primary health care settings in Region B of the Johannesburg Metropolitan Area. 2010 - She is a perment Abstract and grant reviewer for Professional service to the applicants for conferences at Sigma Theta Tau International. Also a member of the International Research Committee of ICN (International Council for Nurses) 


\author{
Health Management and Planning \\ Hajara Bashari \\ Nigerian Air Force Hospital, Nigeria
}

\begin{abstract}
$\mathrm{M}$ anagement and planning are very important items in any organization especially in health care. For any organization to be successful the organization and planning must be combined to achieve the defined goals. Management is the organization and coordination of activities of a business in order to achieve defined objectives. For any organization to excel there is the need to plan the operations and functions of the departments, organize the tasks and assignments by delegating them to the most capable hands. While health planning is the process of defining health problems, identifying unmet needs, surveying the resources to meet them, establishing priority goals that are feasible and realistic, projecting administrative action concerned not only with the adequacy, efficacy and efficiency. Health care planning consists of certain inputs from human and non human resources, and the outputs are result of the input, which are healthy and illness free society. Health care components include universal coverage, leadership and health policies. Health management and planning are designed to serve patients and their needs. The success of this includes implementing the strategic plans and in-cooperate them into daily activities and make them policies. There is the need to carry out these plans, so that success can be achieved, as well as sustaining it. The goals set out cannot be achieved unless there are financial and organizational plans which have to be set in motion. The cost of medical and other functional health care fund is necessary to run these care however, funds are not steady. Health care systems and hospitals are designed to serve patients in all aspects needed. The demand for health care institutions will always be high in which these institutions will need to change that is to understand the future market trends and directions are quite important in order to plan ahead for the patients needs. In order for the healthcare to succeed, managers are appointed to various positions of authority where the organization is shaped by making and taking important decisions. These decisions include recruitment and training of staff, acquisition of equipments and modern technology, service additions and reductions, allocation and spending of financial resources. These healthcare managers make decisions by ensuring that the patient receives appropriate timely and effective services. The functions of management are planning, organization, staffing, controlling, directing and most importantly decision making. The manager to effectively carry out these functions must posses' some skills and competence. Health care planning is also the process of setting goals, developing strategies and outlining tasks and schedules to accomplish these goals. Health care planning can also be seen as the first step in an orderly process to accomplish things necessary to improve health status of individuals and populations. Planning is structured to identify and solve health problems or issues such as
\end{abstract}

- Assessing the current and emerging personal and environmental health needs, resources and development opportunities.

- Formulating goals, objectives, policies and guidelines for long range health resources development.

Health care planning is very important as indicated by the following

- Through identifying health problems

- Identifying unmet needs and surveying the resources to meet such needs

- Establishing priority goals that are realistic and feasible and also projecting administrative planning.

Health planning stages include situation assessment, priority setting, identifying effective strategies, costing scenarios, resource planning and budgeting, programming and implementation, monitoring and evaluation. A good planning should give a clear vision, mission, goals and objectives. This will include the tasks to be executed and the resources to be used thus human resources, materials, money, time, space and information must be included. Planning continuously takes place at all levels in the health systems as well as a collective participation of all professionals that is from the health sectors, government, doterenity and non government organizations. There three types of planning which are strategic, tactical and operational Generally management and planning are very important as well as challenging especially in the health care sectors. One cannot do without the other because it requires people at managerial positions at all levels. For any organization to develop and 
achieve its aims and objectives there must be managerial functions of planning, organization, staffing, controlling and decision making to mention but a few. Planning which is futuristic is an integral part of management thus the aim is to maintain and improve health status of a given community and the populace in general that is to have an ill free society. However this can be achieved by providing health services which are accessible, effective and efficient to ensure appropriate utilization.

\section{References}

1. https//www.who.int $>$ index 5

2. www.slideshare.net.mobile

3. Google

4. www.stratadecision.com

5. Wikipedia

6. Principles of Health Economics For Effective Health Care Management by YM Abdulrazzaq

\section{Biography}

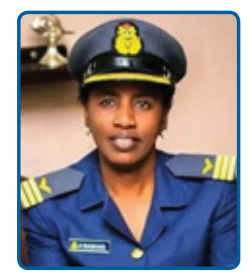

Wing Commander Hajara Bashari is the Commanding Officer Nursing in 063 Nigerian Air Force Hospital Abuja Nigeria. She is in charge of the Nurses and Midwives of the hospital as well as the day to day activities of the hospital. She has a flare for writing and also encourages her subordinates to go into researches on health issues. She is always willing to add more experiences to her years as a nurse/midwife.

\section{Notes:}




\title{
Emotional Labour in Healthcare: A Scoping Review of Literature
}

\section{Paula Diogo}

Lisbon School of Nursing, Portugal

\begin{abstract}
$\mathrm{T}$ he concept of emotional labour is investigated in healthcare by various disciplinary areas, such as sociology, psychology, nursing, medicine and management, but in different perspectives. The purpose of this scoping review is to identify and systematize the production available in research database about the emotional labour in healthcare, not only regarding the distribution of publications, but also the areas of health that have contributed to the development and operationalization of emotional labour, and its conceptualization. The scoping review aims to obtain results extensive and comprehensive and, therefore, with lesser depth on a phenomenon of interest, but shares several characteristics of a systematic review, since it is a methodical process, transparent and replicable. According to the methodology of Arksey \& O'Malley, were initially identified the search terms, later undertook an extensive research, having obtained 136 publications for review, in which predominant scientific literature. Its geographical distribution extends to a set of 26 countries and 5 continents: Europe (United Kingdom, Portugal, Finland, Netherlands, Spain, Turkey, Germany, Ireland, Greece, Denmark, Germany and Hungary); America (Canada, United States of America and Brazil); Asia (China, South Korea, North Korea, Taiwan, Iran, Japan, Taiwan, India and Israel); Oceania (Australia and New Zealand); Africa (Nigeria). The European continent involves the largest number of countries (total of 12) and also the largest number of publications ( $n=86)$, with the United Kingdom in the lead with $39 \%$ of publications $(n=53)$. Regarding the design of emotional labour were identified three areas of focus (Table 1). Nursing was the health area with more publications. There are significant gaps in qualitative and quantitative research, including mix studies, in all groups of health professionals in the Community context, and as well as in conceptual models and clinical studies of emotional labour.
\end{abstract}

\section{Publications:}

1. Bailey S, Scales K, Lloyd J, Schneider J, Rones J (2015) The emotional labour of health-care assistants in inpatient dementia care. Ageing and Society 35: 246-269.

2. Colquhoun H, Levac D, O'Brien K, Straus S, Perrier L, Kastner M, Moher D (2014) Scoping reviews: Time for clarity in definition, methods and reporting. Journal of Clinical Epidemiology 67(12): 1291-1294.

3. Golfenshtein N, Drach-Zahavy A (2015) An attribution theory perspective on emotional labour in nurse-patient encounters: a nested cross-sectional study in paediatric settings. Journal of Advanced Nursing 71: 1123-1134.

4. Smith P (2012) Emotional Labour of Nursing Revisited. Can nurses Still Care? (2a ed.). Hampshire: Palgrave Macmillan.

5. Tuna R, Baykal U (2017) Qualitative Study on Emotional Labour Behavior of Oncology Nurses and its Effects. International Journal of Caring Sciences 10(2): 929-936.

\section{Biography}

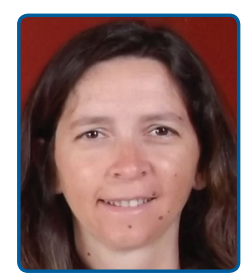

Paula Diogo, author of several paper and books on emotional labour of nursing. She has developed a Model of Emotional Labour in Paediatric Nursing since 2010, aimed at conceptual and operational guidance for the practice of nurses who care for children and youth, and their families, focusing on the emotional management associated with health-disease processes for improving healthcare. She has built this propose Model that has been developed and validated by research (Diogo, 2015, 2017) and taught since 2011. She has a 29 years' experience in nursing and she is a nurse specialist in paediatric health and mental health and psychiatry. 


\author{
Becoming The Mother Of A Second Time: "A Completely Different Experience" \\ Joana Rodrigues \\ Lisbon School of Nursing, Portugal
}

Background: Becoming the mother of a second child, arises from finding a new balance, representing a period of greater vulnerability, with implications for the health and quality of life of the woman and her family members $(1,2)$. A review of the literature shows that research on this phenomenon of transition in parenting is scarce and does not allow a deep understanding of this human experience from a woman's perspective, thus reinforcing the need to explore this area of knowledge (3).

Purpose: understand the lived experience of the woman by becoming the mother of a second child. Methodological orientation: the design of the study adopts a qualitative methodology with hermeneutic phenomenological approach. Data collection was carried out in two day care centers in the Leiria area. Experiential material was collected from phenomenological interviews with eleven women, with a second child, who at the time of the interview was between 18 and 24 months of age. The activities developed in the data analysis process took into account the van Manen approach $(4,5)$.

Results: becoming a mother of two emerged as "a completely different experience", insofar as two children, one family, require the accomplishment of innumerable activities by the woman, leading to the experience of "very" and "limit", to go beyond the search for a new self, which wants to find the essentials. This experience leads to decision-making, prioritization and can lead to attrition and illness. The search for help is the path taken by women in a time in which you need more.

Conclusion: Through this study, nurses will be able to access the lived experience of these women and with these findings improve their intervention.

\title{
Publications:
}

1. O’Reilly M. Achieving a new balance: women's transition to second-time parenthood. JOGNN: Journal of Obstetric, Gynecologic \& Neonatal Nursing. 2004; 33(4): 455-462.

2. Vivian A. Tornar-se mãe de um segundo filho: da gestação ao segundo ano de vida. Universidade Federal do Rio Grande do Sul. 2010. [cited 20183 june]. Available from: https://www.lume.ufrgs.br/bitstream/handle/10183/26812/000761032. pdf?sequence $=1$

3. Rodrigues J, Velez M. Tornar-se mãe de um segundo filho: uma revisão scoping. Pensar Enfermagem. 2018; 22 (1): 5-17.

4. van Manen M. Researching lived experience, human science for an action sensitive pedagogy. 2 ed. Ontario: The Althouse Press. 2003.

5. van Manen M. Phenomenology of practice: meaning-giving methods in phenomenological research and writing. Walnut Creek: Left Coast Press, cop. 2014.

\section{Biography}

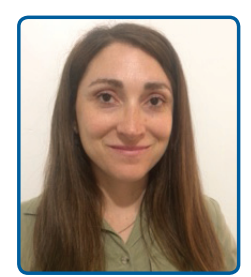

Joana Rodrigues - Nurse for 14 years, currently in the community, with Specialization in Child and Pediatric Health Nursing. From 2011 collaborates with the School of Nursing of Lisbon. Researcher at nursing research \& development unit (ui\&de). Currently completing a doctorate degree in nursing.

Notes: 


\author{
Safe Management of Patient Violence: Effective Training Programs for Nurses at Risk for Violence \\ in Today's Medical Centers \\ Sally C Duron \\ California State University, USA
}

The incidence of patient to nurse violence in hospitals and other healthcare facilities is increasing across the USA. RNs and
other healthcare workers are likely to experience 3 to 4 times higher non-fatal injuries than for all industry. Exposure to
violence in healthcare is not limited to the USA but has also affected other countries. Presently research is being done in both
the USA and Europe on the impact patient violence has on nurses. Statistics and research validates an increase verbal abuse
and physical assaults on nursing personnel delivering patient care in a variety of clinical settings. At risk areas for patient to
nurse violence is no longer limited to Mental Health and Emergency Services but now extends to venues including medical
units, clinics, and social services. Mandatory training for nurses and other healthcare personnel is quickly being implemented
throughout the USA that address patient violence. California has recently implemented regulations requiring specific training
for all healthcare professionals in the prevention and management of patient violence. Additional training such as workplace
violence and active shooter training has been included. The physiological and psychological injuries inflicted on nurses has
directly impacted 1) increase absences from work 2) a decrease in healthcare workforce 3 ) and negative outcomes associated
with patient care delivery. Research validates that hospital base programs offering training and skills competencies on crisis
intervention has reduce such consequences. A benchmark on the development and implementation of successful training
programs will be shared in this presentation.

\title{
Publications:
}

1. The Joint Commission. Improving Patient and Worker Safety: Opportunities for Collaboration \& Innovation. Oakbrook, IL.2012

2. Phillips JP. Workplace Violence Against Healthcare workers in the United States. New England Journal of Medicine, 2016; 374 (17):1661-9

Biography

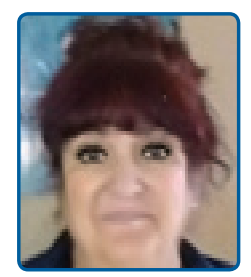

Sally Duron is presently an adjunct professor at California State University, San Bernardino, CA and West Coast University Ontario, CA. She is a Prevention and Management of Assaultive Behavior (PMAB) instructor. She has many years of experience as a Nurse Educator in the development of educational programs for medical professionals and students both within hospital educational institutes. She has a passion for integrating safe practice in all aspects of nursing care to improve the patience care experience. Her active participation in hospital base Performance Improvement, Safety, and Risk Management committees has allowed her to evaluate current risk factors, interventions from evidence base crisis models, and how to develop effective training programs that meet both professional and student competencies in management of patient violence in today's healthcare environment.

\section{Notes:}




\section{NURSING AND HeALTHCARE}

\section{July 15-17, 2019 | Rome, Italy}

\section{High blood pressure in children and adolescents: a public health problem?}

Fabiane Rosa Rezende Honda Marui

Paulista University, Brazil

$\mathrm{H}^{2}$ ypertension in children and adolescents has become frequent due to the increase in the percentage of obesity in this age group. In the American, Chinese and European children and adolescents, the prevalence of overweight is over $30 \%$. In Brazil, it is estimated that $25 \%$ of adolescents are overweight. An untreated hypertensive child or adolescent will be an adult with the possibility of developing early cardiovascular and renal comorbidities, causing a great impact on public health. The campaigns for the detection and follow-up of hypertension include the adult and elderly population. It is uncommon to measurement of the BP in children and adolescents routinely. Most parents and health professionals are unaware of the risk of obese children and adolescents presenting BP elevation. Thus, studies in the pediatric population to detect alterations in blood pressure values and behavior should be performed in order to provide data that support the practice and make the health professional aware of the diagnosis and early treatment of hypertension.

Objective: To discuss the importance of the detection of hypertension in children and adolescents through the awareness of health professionals regarding the measurement of blood pressure in childhood and adolescence.

\section{Publications:}

1. Muntner P, He J, Cutler JA, Wildman RP, Whelton PK. Trends in blood pressure among children and adolescents. JAMA 2004;291:2107-13.

2. Moreno LA, Mesana MI, Fleta J, Ruiz JR, González-Gross M, Sarría A et al. Overweight, obesity and body fat composition in Spanish adolescents. The AVENA Study. Ann Nutr Metab 2005;49:71-6.

3. Li Y,Yang X, Zhai F, Piao J, Zhao W, Zhang J et al. Childhood obesity and its health consequence in China. Obes Rev 2008;9 (Suppl 1):82-6.

\section{Biography}

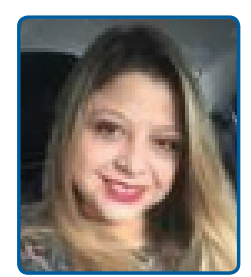

Fabiane Marui is specialist in cardiovascular nursing with focus on hypertension and blood pressure monitoring. She is a graduate from the Nursing School - USP (Universidade de São Paulo, Brazil), where same institution in which she is currently candidate for a postgraduate degree in public health. He holds a master's and doctorate in cardiology from the Universidade Federal de São Paulo (UNIFESP). She is a nursing professor at the Universidade Paulista (UNIP) and the Universidade Municipal de São Caetano do Sul (USCS).

\section{Notes:}




\author{
Female Genital Cutting (Fgc) Digital Book and Online Resource: Nursing-Midwifery Care Context \\ Najla Barnawi \\ King Saud Bin Abdulaziz University for Health Sciences, Kingdom of Saudi Arabia
}

Purpose/Aim: The purpose of this workshop is to test the effectiveness of a FGC digital book in improving the nurse- midwives/ midwives' attitude, knowledge and self-efficacy with clinical decision making when caring for women who have undergone FGC.

Background: FGC affects at least 200 million women worldwide. Due to increasing transmigration, care of women with FGC has become a national and global public health and human rights issue. However, caring for women with FGC, particularly pregnant women, is a key challenge within the healthcare context. This challenge occurs because there is a lack of understanding the socio-cultural aspects of FGC and lack of knowledge of how to manage the complications that are associated with it. This leads to decrease the trust-relationship, which decreases the potentialities to initiate an effective therapeutic communication.

Significance: The FGC Digital eBook is an electronic version of a traditional print book, which can easily accessed by any personal laptops, smart phone, iPad, or tablet. Adult Learning Theory (ALT) is the theoretical framework for this study as it is targeting adult populations. Integrating ALT emphasizes the self-reflective learning strategy, which enhances effective learning-engagement. Therefore, the participants can set, achieve, and monitor their personal progress through the course. The eBook highlights all clinical controversies that concern FGC in a professional and attracting way. Indeed, it represents the social aspects at different historical periods and within different cultural contexts. Such information assists the nurse-midwife/ midwife to provide a competent clinical and socio-cultural care.

Methods: A pre-post test quasi-experimental design will be conducted with a convenience sample of nurses and/or nursemidwives. The FGC attitude scale, which had been developed to assess the level of negative and positive attitudes towards some aspects of FGC includes 13 (7 positive attitude and 6 negative attitude) close-ended questions that had 5-point Likert scale. Each positive attitude question is categorized as (strongly disagree [1], disagree [2], neutral [3], agree [4] and strongly agree [5]). This concludes that the total score for the positive attitude subscale ranges between (7 to 35), where 7 indicate the lowest and 35 is the highest. However, each negative attitude question is categorized as (strongly disagree [5], disagree [4], neutral [3], agree [2] and strongly agree [1]). This concludes that the total score for the negative attitude subscale ranges between ( 7 to 35), where 7 indicate the lowest and 35 is the highest. The knowledge scale, which been developed to assess the level of FGC knowledge has 14 close-ended questions. Each question is categorized as (true=3), (uncertain=2), and (false $=1$ ). Therefore, the total scale score ranges from 14 to 42 ; while 14 indicate the lowest score, and 42 indicate the highest. The FGC self-efficacy scale has 14 close-ended questions. Each question is categorized as no, which is scored as ( $1=$ neither yes nor no), $(2=\mathrm{No})$; and ( $3=$ Yes). Therefore, the total scale score ranges from 36 to 108; while 36 indicate the lowest score, and 108 indicate the highest. T-test for dependent sample will assess the statistical significance.

Discussion: ACNM and ICM essential competencies highlight the need for midwives to deepen their understanding of FGC to provide competent perinatal care. They emphasize the importance of demonstrating knowledge, skills, and abilities to manage the complications of various degrees of FGC that may occur during perinatal care including the birth process.

\title{
Biography
}

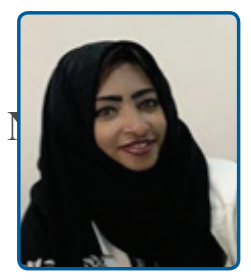

Najla Barnawi is a Saudi Assistant Professor in the College of Nursing at King Saud University for Health Sciences. Dr. Barnawi graduated (2004) from King Saud University (KSU) as one of the Saudi pioneers in the nursing profession with excellent and honor certificates from Nursing Bachelor program at KSU. She was the 1st Saudi nurse who earned her master program in 2007 from Lawrence S. Bloomberg Faculty of Nursing at the University of Toronto, Canada. She worked as faculty member and researcher in various national and international universities. Dr. Barnawi eared her Ph.D. with excellence and outstanding honor certificate at the university level from Decker School of Nursing at Binghamton University in the US. She received the Sigma Theta Tau Award for the best Ph.D. dissertation and Outstanding Student Award from Binghamton University. Her Ph.D. focuses on developing effective learning and teaching methods to expand the knowledge and self-efficacy of nurses and midwives to promote the quality of health of minority population and cultural competency. She was the vice president for Saudi Student in New-York Binghamton in the Saudi Arabian Cultural Mission from 20162018. Currently, besides her teaching position, she is the chairperson of the Community Services Unit at the College of Nursing at KSAU-HS. 


\title{
NuRsing ANd HeALTHCARE
}

\section{July 15-17, 2019 | Rome, Italy}

\author{
Law Enforcement Attitudes Towards Naloxone Following Opioid Overdose Training \\ Donna Purviance \\ Indiana State University, USA
}

Background: Opioid intoxication and overdoses are life-threatening emergencies requiring rapid treatment. One response to this has been to train law enforcement to detect the signs of an opioid overdose and train them to administer naloxone to reverse the effects. Although not a new concept, few studies have attempted to examine this policy.

Methods: At four different locations in Indiana, law enforcement personnel were trained to detect the signs of an opioidrelated overdose and how to administer naloxone to reverse the effects of the overdose. Pre and post surveys were administered at each location $(\mathrm{N}=97)$. To examine changes in attitudes following training, the authors included items from the Opioid Overdose Attitudes Scale (OOAS), which measures respondents' competency, concerns, and readiness to administer naloxone.

Results: Among the full sample, naloxone training resulted in significant increases in competency, concerns, and readiness. Examining changes in attitudes by each location revealed that the training had the greatest effect on competency to administer naloxone and in easing concerns that law enforcement personal might have in administering naloxone.

Conclusions: This study adds to others in showing that law enforcement personnel are receptive to naloxone training and that the OOAS is able to capture these attitudes. This study advances the literature by examining pre-post changes across multiple locations. As the distribution of naloxone continues to proliferate, this study and the OOAS may be valuable towards the development of an evidence-based training model for law enforcement.

\section{References:}

1. Smith, R.M., Manifold, C., \& Wampler, D.A. (2013). San Antonio police department launces tactical medic program. Specially trained officers can deliver emergency care until EMS takes over. EMS World, 42, 45-49

2. Williams, AV., Strang, J., Marsden J. (2013). Development of Opioid Overdose Knowledge (OOKS) and Attitudes (OOAS) Scales for take-home naloxone training evaluation. Drug Alcohol Depend. 132, 383-386. Doi:10.1016/j. drugalcdep.2013.02.007

Biography

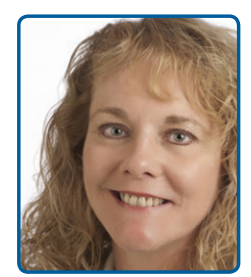

Donna Purviance has 10 years of expertise as a Family Nurse Practitioner (FNP) and is an Assistant Professor in the Department of Advanced Practice Nursing, School of Nursing at Indiana State University. Donna is a FNP educator and practices in an urgent care setting. Her passion is treating and expanding knowledge in the areas of chronic pain, acute pain, and addiction, specifically opioid use disorder/addiction through policy development and education. She has served on the Indiana Attorney General's Prescription Drug Task Force since 2013. Given her expertise, she has been a sought after as a speaker on the topic of opioid addiction and chronic pain.

\section{Notes:}




\title{
July 15-17, 2019 | Rome, Italy
}

\author{
Social Media: Exploring Adolescent Mental Health Risks \\ Jessica Durbin \\ Indiana State University, USA
}

Background: Social media use has become increasingly popular among teens and adolescent $\mathrm{s}$ during the past decade. Technologic advancements have led to an increase in Internet use and virtual communication through computers, cellphones, and tablet s. The prevalence of social media use is leading to an increased understanding of the risks associated with it. Approximately $92 \%$ of teens state that they use the Internet daily, and $71 \%$ use at least two different types of social media sites. Current research indicat es $t$ hat signs and sympt oms of depression may be relat ed t o prolonged use of social networking sites, such as Facebook, and that low self-esteem may be associated with certain social networking activities. Furthermore, studies indicate overall social media use, emotional investment in social media, and night time-specific social media use were associated with higher levels of anxiety and depression, risk for self-harming behaviors, suicide risk, lower self-est eem, and poorer sleep qualit $\mathrm{y}$ in adolescent s ages.

Purpose / Goal: The use of social media can have negative mental health consequences on the adolescent population and in severe cases lead t o depression, suicide ideat ion, att empt $s$ and complet ion. It is import ant across disciplines as healthcare providers, school social workers and counselors, parents, $t$ eachers, and t he adolescent population itself $t o$ be aware of $t$ hese effect $s$ and $t o t$ ake precaut ions in order $t$ o prevent $t$ hese negat ive out comes. Having knowledge of $t$ he risk fact ors, detriment al effects of use and investing in ways to appropriately intervene is paramount to healthy out comes for our adolescent population.

Conclusion: Theses findings have practical value for healthcare providers, parents, and teachers. An important role for all includes becoming familiar with the different types of social media out let $s$ and the usage of these sites, as well as length of time spent using social media by the adolescent population they care for. Knowing these sites are outlets for adolescents to send and receive different information about themselves to friends as well as strangers. Parents and teachers should be aware that profiles on these sites are open for the public to see unless there is a privacy set ting that is manually set up. Another important role is to include routine screenings to assess the risk of depression associated with social media use. Tools should be developed to help providers engage in conversations that inquire about online contacts, incidence of being cyberbullied, and assessing the time spent on social media. When precautions and screening are in place there is a bet ter chance of combating the negat ive effects of social media. Further research is needed to identify adolescents that are at a higher risk for negative consequences of social media and provide strategies that will allow them to avoid or manage the risks. Further research could also focus on the amount adolescents are invested in their social networking and less focus on how they are using t heir social networking sites. In addition, further guidance is needed for healthcare providers and parents on the appropriate social media use with adolescent s.

\section{References:}

1. American Academy of Child \& Adolescent Psychiatry (2011). Fact s for Families pages-Children and social networking. Retrieved from http://www.aacap.org/AACAP/Families_and_Yout h/Fact s_for_Families/FFF-Guide/Children-andSocial-Net working-100.aspx

2. Bhagat, S.(2015). Is Facebook a planet of lonely individuals? A review of literature. The International Journal of Indian Psychology, 3(1), 5-9.

3. Blomfield Neira, C.J., \& Barber, B. (2014). Social networking site use: Linked to adolescents' social self-concept , self-est eem, and depressed mood. Aust ralian Journal of Psychology, 66, 56- 64.

4. Chapin, J. (2016). Adolescent s and cyber bullying: The precaut ion adopt ion process model. Education Information Technology, 21, 719-728.

5. Hawton, K., Saunders, K. E., \& Oconnor, R. C. (2012). Self-harm and suicide in adolescent s. The Lancet, 379(9834), 2373-2382. doi:10.1016/s0140-6736(12)60322-5 


\section{July 15-17, 2019 | Rome, Italy}

\section{Biography}

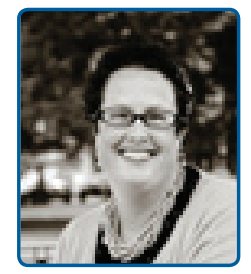

I am a Family Nurse Practitioner skilled in acute care and family practice. I am currently an Assistant Professor and FNP Program Director in the Advanced Practice Nursing Department at Indiana State University. My nursing background was neonatal intensive care, pediatric and adult trauma. I have over 10 years clinical experience as a Family Nurse Practitioner, and 9 years of $t$ eaching in $t$ he graduat $e$ nursing program at ISU. I have published mult iple art icles on Adolescent healt $\mathrm{h}$ issues and present ed at local and regional conferences on the $t$ opic of social media risks in the adolescent populat ion.

\section{Notes:}




\title{
NuRsing AND HeALTHCARE
}

\section{July 15-17, 2019 | Rome, Italy}

\author{
The knowledge of the adolescents about sexuality: Has guidance been effective? \\ Fabiane Rosa Rezende Honda Marui \\ Paulista University, Brazil
}

Introduction: Sexuality in adolescence is a relevant issue for public health because of the epidemiological risk it presents. In Brazil, countless schools and health professionals have developed activities for adolescents over the age of 14 in order to prevent sexually transmitted infections (STIs), unplanned pregnancies and, through information, minimize undesirable conditions that can affect life of many young people, such as school disruption, depression and insecurity.

Objective: To verify the knowledge about sexuality of adolescents living in a neighborhood located in the western zone of São Paulo.

Method: An exploratory descriptive study, conducted in the city of São Paulo, Brazil, with 50 adolescents with active sexual life, by signing the informed consent form.

Results and discussion: The research was done with 30 adolescents. The adolescents participating in the study had the age group between 14 and 20 years of age, with 33.3\% (10) males, most of whom were single (83.3\%) and 36.78\% started sexual activity less than one year. And $46.6 \%$ reported not being aware of the main sexually transmitted infections. Although they have information for the prevention of early pregnancy and STI, most are unaware of the main STIs (46.6\%). The majority of the interviewees $(73.3 \%)$ referred to learning about sexuality in school.

Conclusion: The school is where adolescents spend most of their time, establishing links and talking about their doubts and problems. Thus, the school environment is ideal for these young people to acquire knowledge about sexuality. The partnership between the school, health professionals and family members can facilitate the bond with the adolescent. Projects such as workshops and lectures and encouragement to parents to participate with the children of these projects can break the embarrassment between parents and children, facilitating the approach of the theme in a family environment.

\section{References:}

1. Genz N, Meincke SMK, Carret MLV, Corrêa ACL, Alves CN (2017) Sexually transmitted diseases: Knowledge and sexual behavior of adolescents. Texto contexto Enferm, 26(2): e 5100015.

2. Fiedler MW, Araújo A, Souza MCC (2015) The prevention of teenage pregnancy in adolescent's view. Texto contexto enfem, Florianópolis, 24(1): 30-7.

3. Malta EC, Martins MR, Almeida MF (2013) Evaluation of the knowledge of adolescents about sexually transmitted infections. Rev enferm UFPE on line. Recife 7 (esp):7042-7.

4. Sousa LB, Fernandes JFP, Barroso MGT (2006) The influence of family cultural beliefs on adolescent's sexual behavior. Acta paul. Enferm, vol.19, n.4, pp.408-13

5. Teixeira AMFB, Knauth DR, Fachel JMG, Leal AF (2006) Teenagers and condom use: choices by young Brazilians from three Brazilian State capitals in their first and last sexual intercourse. Cad saúde pública, Rio de Janeiro, 22(7): $1385-96$.

Biography

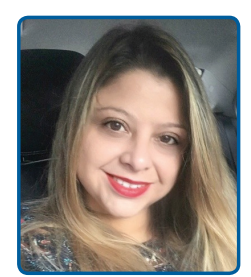

Fabiane Marui is specialist in cardiovascular nursing with focus on hypertension and blood pressure monitoring. She is a graduate from the Nursing School - USP (Universidade de São Paulo, Brazil), where same institution in which she is currently candidate for a postgraduate degree in public health. He holds a master's and doctorate in cardiology from the Universidade Federal de São Paulo (UNIFESP). She is a nursing professor at the Universidade Paulista (UNIP) and the Universidade Municipal de São Caetano do Sul (USCS). 


\title{
NuRsing ANd HeALTHCARE
}

\section{July 15-17, 2019 | Rome, Italy}

\author{
Incidence of stress urinary incontinence in late pregnancy \\ Fabiane Rosa Rezende Honda Marui \\ Paulista University, Brazil
}

Introduction: Late gestation is one that occurs after the woman's 35 years, due to physiological adaptation is a common complaint among pregnant women the involuntary loss of urine that characterizes urinary incontinence.

Objectives: To identify the incidence of stress urinary incontinence (SUI) in pregnant women over 35 years of age.

Methodology: Quantitative descriptive field study, by means of the application of a questionnaire to 30 late pregnant women, after obtaining the approval of the Ethics Committee.

Results: Of the 30 women interviewed, 25 reported symptoms of SUI, especially in the first trimester of pregnancy, related to discomfort and interference in daily activities, there was no differentiation between those cited by pregnant women in other age groups and without SUI symptoms.

Conclusion: The incidence was $83.3 \%$; the first trimester was the most prevalent; the discomfort and interference in the activities of late pregnant women with SUI did not present themselves as worse than in pregnant women of the other ages or without the symptoms of SUI.

\section{References:}

1. Farias TC, Morais KCS, Cirqueira RP, Albuquerque LS, Ferreira JB. Incontinência urinária e disfunção sexual em gestantes. Id on Line Revista De Psicologia. 2017.11(38), 237-48.

2. Pinheiro A, Oliveira J, Matos N, Moussa L, Mendes M. Estudo da prevalência de sintomas da incontinência urinária de esforço durante o período gestacional em primigestas: Revista Pesquisa E Ação. 2017, 3(2), 93-106.

3. Pereira SVM, Bachion MM. Nursing Diagnoses identified in pregnant patients under prenatal care. Rev bras enferm, 2015.58(6), 659-64.

4. Stumm K, Santos CC, Ressel LB. Tendência de estudos acerca do cuidado pré-natal na enfermagem no Brasil. Rev Enferm UFSM. 2012 v.2, n.1, p. 165-73.

5. Busanello J, Lunardi Filho WD, Kerber NPC, Lunardi VL, Santos SSC. Woman's participation in the decision process of the pregnancy and puerperal cycle: nursing care integrative review. Rev Gaucha Enferm. 2011;32(4):807-14.

Biography

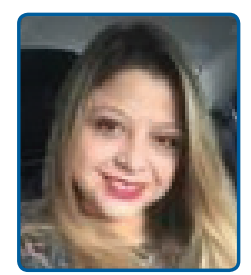

Fabiane Marui is specialist in cardiovascular nursing with focus on hypertension and blood pressure monitoring. She is a graduate from the Nursing School - USP (Universidade de São Paulo, Brazil), where same institution in which she is currently candidate for a postgraduate degree in public health. He holds a master's and doctorate in cardiology from the Universidade Federal de São Paulo (UNIFESP). She is a nursing professor at the Universidade Paulista (UNIP) and the Universidade Municipal de São Caetano do Sul (USCS).

\section{Notes:}




\title{
Emotional Labour in Healthcare: A Scoping Review of Literature
}

\section{Paula Diogo}

Lisbon School of Nursing, Portugal

\begin{abstract}
$\mathrm{T}$ he concept of emotional labour is investigated in healthcare by various disciplinary areas, such as sociology, psychology, nursing, medicine and management, but in different perspectives. The purpose of this scoping review is to identify and systematize the production available in research database about the emotional labour in healthcare, not only regarding the distribution of publications, but also the areas of health that have contributed to the development and operationalization of emotional labour, and its conceptualization. The scoping review aims to obtain results extensive and comprehensive and, therefore, with lesser depth on a phenomenon of interest, but shares several characteristics of a systematic review, since it is a methodical process, transparent and replicable. According to the methodology of Arksey \& O'Malley, were initially identified the search terms, later undertook an extensive research, having obtained 136 publications for review, in which predominant scientific literature. Its geographical distribution extends to a set of 26 countries and 5 continents: Europe (United Kingdom, Portugal, Finland, Netherlands, Spain, Turkey, Germany, Ireland, Greece, Denmark, Germany and Hungary); America (Canada, United States of America and Brazil); Asia (China, South Korea, North Korea, Taiwan, Iran, Japan, Taiwan, India and Israel); Oceania (Australia and New Zealand); Africa (Nigeria). The European continent involves the largest number of countries (total of 12) and also the largest number of publications ( $n=86)$, with the United Kingdom in the lead with $39 \%$ of publications $(n=53)$. Regarding the design of emotional labour were identified three areas of focus (Table 1). Nursing was the health area with more publications. There are significant gaps in qualitative and quantitative research, including mix studies, in all groups of health professionals in the Community context, and as well as in conceptual models and clinical studies of emotional labour.
\end{abstract}

\section{References:}

1. Bailey S, Scales K, Lloyd J, Schneider J, Rones J (2015) The emotional labour of health-care assistants in inpatient dementia care. Ageing and Society 35: 246-269.

2. Colquhoun H, Levac D, O'Brien K, Straus S, Perrier L, Kastner M, Moher D (2014) Scoping reviews: Time for clarity in definition, methods and reporting. Journal of Clinical Epidemiology 67(12): 1291-1294.

3. Golfenshtein N, Drach-Zahavy A (2015) An attribution theory perspective on emotional labour in nurse-patient encounters: a nested cross-sectional study in paediatric settings. Journal of Advanced Nursing 71: 1123-1134.

4. Smith P (2012) Emotional Labour of Nursing Revisited. Can nurses Still Care? (2a ed.). Hampshire: Palgrave Macmillan.

\section{Biography}

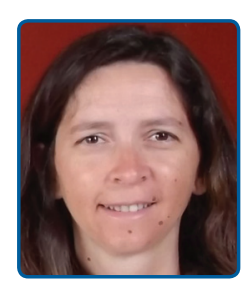

Paula Diogo, author of several paper and books on emotional labour of nursing. She has developed a Model of Emotional Labour in Paediatric Nursing since 2010, aimed at conceptual and operational guidance for the practice of nurses who care for children and youth, and their families, focusing on the emotional management associated with health-disease processes for improving healthcare. She has built this propose Model that has been developed and validated by research (Diogo, 2015, 2017) and taught since 2011. She has a 29 years' experience in nursing and she is a nurse specialist in paediatric health and mental health and psychiatry.

\section{Notes:}




\title{
Becoming a mother of a second child: A scoping review of literature
}

\section{Joana Rodrigues}

Lisbon School of Nursing, Portugal

\begin{abstract}
$\mathrm{B}$ ecoming the mother of a second child, as a transitional phenomenon in parenting, represents a unique period of transformation and greater vulnerability. By becoming a mother for the second time, the woman is confronted with specific problems of this period of the life cycle, inasmuch the uniqueness of each baby is connected to a particular moment in the woman's life, whom needs to become the mother of a new being and welcome each child into her own life and that of the family. The evidence that portrays this transition remains scattered in the literature. In this sense, in order to identify and map the available scientific evidence on the transition of women to become the mother of a second child, a scoping review was carried out that followed the methodology recommended by the Joanna Briggs Institute. Nine studies published between 1997 and 2013 were identified. The studies were carried out mainly in the United States, Northern Europe and the Netherlands. Its participants and the time of data collection differed. In one study only the participants were female mothers of a second child. The data collection was mainly between the third trimester of pregnancy and the 12 months of life of the second child. One study investigated women's experience of becoming the mother of a second child and identified the elements common to the lives of these women, while gender and conjugality emerged in the rest.We conclude that the involved studies were published over sixteen years, presenting some elements that characterize this transition. This being a period of the life cycle that requires nursing care, aimed at strengthening skills, more studies must be done, namely in order to explore the perceptions of women about this stage of the life cycle.
\end{abstract}

\section{Publications:}

1. Holditch-Davis, D., \& Miles, M. (2012). Parenting research in nursing. In Encyclopedia of Nursing Reasearch (Third edit.). NY: Springer Publishing Company.

2. Meleis, A. (2010). Transitions theory: middle range and situation specific theories in nursing research and practice. New York: Springer Publishing Company LLC.

3. Mercer, R. T. (2004). Becoming a Mother Versus Maternal Role Attainment. Journal of Nursing Scholarship, 36(3), 226-232.

4. O'Reilly, M. (2004). Achieving a new balance: women's transition to second-time parenthood. JOGNN: Journal of Obstetric, Gynecologic \& Neonatal Nursing, 33(4), 455-462.

5. The Joanna Briggs Institute (2015). The Joanna Briggs Institute Reviewers' Manual 2015: Methodology for JBI Scoping Reviews. South Australia: The Joanna Briggs.

\section{Biography}

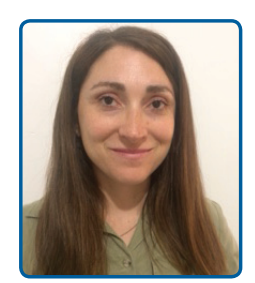

Joana Rodrigues - Nurse for 14 years, currently in the community, with Specialization in Child and Pediatric Health Nursing. From 2011 collaborates with the School of Nursing of Lisbon. Researcher at nursing research \& development unit (ui\&de). Currently completing a doctorate degree in nursing.

\section{Notes:}




\title{
July 15-17, 2019 | Rome, Italy
}

\author{
Violence against the Nursing Staff \\ Yaser Sweed \\ Galilee Medical Center, Israel
}

$\mathrm{T}_{\mathrm{s}}$ he phenomenon of violence against the medical staff at the hands of patients and those accompanying with them is

1 recognized today as one of the difficult problems that hospitals and clinics in the community are dealing with. The problem is steadily worsening in parallel to the rise in violence in Western society in general and in Israel in particular. The objective of this research study is to examine the perceptions of the nursing staff regarding the causes of violence towards the staff and to identify possible risk factors of violence towards the staff in the acute internal medicine department, in the chronic disease departments, and in the emergency medicine department. A total of 134 nursing staff members, 82 from internal medicine departments, 28 from chronic disease departments, and 24 from emergency medicine departments, participated in the research. The age mean was $40.2 \pm 9.5$, the professional experience was $14.9 \pm 10.2$, and the experience in the department was 10.6 \pm 8.3 . The conclusions of the research are that risk factors for the creation of violence are similar in all the departments. In addition, we identified a clear trend that the rate of exposure to violence of the nursing staff is similar in all the departments. Therefore, it is very important to develop instruments for coping with violence among the staff. Most of the participants indicated that their training in the topic is deficient and that in their opinion it is important to provide appropriate training to the staff. It was further found that in the departments there is a feeling that the handling of the cases of violence is deficient, and therefore emphasis should be placed on this topic and the departments should be strengthened through means that reduce the workers' stress and increase their safety.

\section{Publications:}

1. Bonner G.P (2012). Touched by violence and caring for the violator: The lived experiences of nurses who were assaulted by their patients in psychiatric settings. Doctoral dissertation,Capella University

2. Bradley D.M (2012). A qualitative study of violence and victimization perpetrated against registered nurses in the workplace. Doctoral dissertation, Capella University.

3. Hahn S., Muller M., Needham I., Dassen T., Kok G., \& Halfens R. JG (2010). Factors associated with patient and visitor violence experienced by nurses in general hospitals in Switzerland: a cross-sectional survey. Journal of Clinical Nursing, 19, pp. 3535- 3546.

4. Healy. s., and Tyrell M. (2011). Stress in emergency department experiences of nurses and doctors. Emergency nurse 19(4), Pp. 31-37.

\section{Biography}

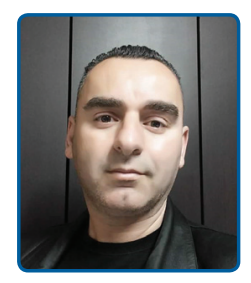

Yaser Sweed was born in the village of Peqiin in 1970. He studied elementary and high school in the village and finished high school in the galilee comprehensive school. He decided to continue his studies and chose the profession of nursing, at the Shaare Zedek nursing school in Jerusalem. He has a bachelor's degree in health systems management and today he continue his MA in the same field. He work in an internal ward at a Galilee medical center in Naharya.

\section{Notes:}




\author{
Factors That Affect the Use of Nursing Policies and Protocols \\ Geneva M Edwards \\ Investigative Medicine LLC, USA
}

Introduction: Nursing policies and protocols (P\&Ps) have been shown to be beneficial in improving patient outcomes.1,2 However, the extent to which nurses use P\&Ps as part of their routine care in unknown.3-4

Purpose: The aims of this study were to: a) Explore nurses' use of P\&Ps to guide routine practice, and b) Identify barriers and facilitators affecting the frequency of their use.

Methods: This was an exploratory, descriptive study of licensed nurses $(\mathrm{N}=235)$ providing direct care to patients in outpatient and inpatient settings in a VA Health Care System. Data were gathered using an 18-question on-line survey that was accessible through an VA-approved vendor during a two-week period in April 2018.

Results: There was an overall response rate of $45.1 \%(\mathrm{~N}=235)$. Not all respondents answered all survey items $(\mathrm{n}=227-235)$. The majority $(84.5 \%)$ of respondents were RNs, $79,5 \%$ had a BSN or higher, and $81.2 \%$ had more than 6 years of practice experience; $52.0 \%$ worked in outpatient settings. Most respondents $(n=129) ; 44.8 \%$ reported accessing policies and protocols greater than monthly, $47.9 \%$ accessed them less than monthly, and 7.3\% never accessed them. Most received information about new P\&Ps by email, 58.7\%. The most frequently reported barrier to using P\&Ps was that they were difficult to locate; lack of time was not a significant factor. Frequent versus infrequent use varied by Age Group: Baby Boomers 38.8\%, Generation X, 49.5\%, Millennials, 50.0\%, Role: RNs (86.6\%) v. LPNs (63.6\%) and Years of Experience as Licensed Nurses: > 3 yrs. (84.3\%) v.< 3 yrs. (50.0\%). Strategies to make P\&Ps user friendly included more effective communications, more in-service education, and removing outdated information from $\mathrm{P} \& \mathrm{P}$ embedded in the electronic health record.

Discussion and Conclusions: At present, there is no known standard for the optimum use of P\&Ps to maximize patient outcomes, but given these results, institutions may want to make P\&Ps easy to access and read, to meet the needs of practicing nurses.

\title{
Publications:
}

1. Popovich, M., Boyd, C., Dachenhaus, T., \& Kusler, D. (2012). Improving stable patient flow through the emergency department by utilizing evidence-based practice: One hospital's journey. Journal of Emergency Nursing, 38, 474-478.

2. Yupha, W., Warunee, F., Nitaya, P., \& Hanneman, S. K. (2016). A qualitative study of factors affecting sustainable implementation of a mechanical ventilation weaning protocol. Pacific Rim International Journal of Nursing Research, 20, 132-147.

3. Powers, K. A. \& Candela, L. (2017). Nursing practices and policies related to family presence during resuscitation. Dimensions of Critical Care Nursing, 36, 53-59.

\section{Biography}

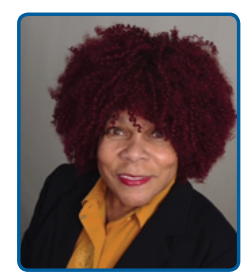

Edwards is a seasoned medical professional with $35+$ years of experience. She is a Registered Nurse, a Board Certified Medical Investigator, Legal Nurse Consultant, and a medical writer. She holds a Bachelor of Science in Nursing, a Master's in Health Administration, and a Medical Doctorate degree. She completed post-doctoral fellowship training in researching and analyzing medical data at CDC in Atlanta Georgia. Her passion lies in caring for the elderly and investigating what happens when medicine and law collide. For the last 8 years, Dr. Edwards has volunteered healthcare services to 3rd world countries, giving her the prestigious names of Dame of Honor, Dame of Grace and Grand Dame of the Cross. 


\title{
Assessing the effectiveness of lecture method versus visual, auditory, reading and kinesthetic (vark) methods in teaching and learning in a private nursing educational institution
}

\author{
Tania Normal Lynette Antill \\ Masters student at the University of the Witwatersrand.
}

Background: It was anticipated that students' performance will improve through the shift from the traditional lecture method of teaching to different teaching styles such as visual, auditory, reading and kinaesthetic (VARK).

Objectives: This study examined whether VARK method of teaching and learning is more effective than the traditional lecture method in improving educational outcomes in nursing students.

Methods: A two (2) group pretest post-test crossover experimental design using Multiple-Choice Questions was used for this study. An open-ended question was asked in order to determine the students' perception. Data was analysed using descriptive and statistics including the means of the pre- and post-test scores.

Results: There was evidence $(\mathrm{t}=3.7910$, $\mathrm{p}$-value $=0.0003)$ that overall the traditional method of teaching improved the scores obtained by the participants on average by $\mathrm{t}=4.428571$. The VARK teaching method improved the scores by $\mathrm{t}=4.571429$. Although the VARK teaching method improved participants score on average by $t=0.1428571$, the $p$-value of 0.9334 demonstrates that the differences in means is not statistically significant. The results obtained from the open-ended question revealed that $65.14 \%$ of the participants preferred VARK, and $27.12 \%$ preferred traditional and $7.14 \%$ preferred both methods of teaching.

Conclusion: The insights gained from this research report highlight the need for a diversity of teaching and learning methods for nursing students. Although no significant improvement were noted, the integration of VARK teaching method into nursing education is essential to improve students' performance.

\section{Biography}

\section{Notes:}

